\title{
Distribution of phytoplankton functional types in high-nitrate, low-chlorophyll waters in a new diagnostic ecological indicator model
}

\author{
A. P. Palacz ${ }^{1}$, M. A. St. John ${ }^{1}$, R. J. W. Brewin ${ }^{2}$, T. Hirata ${ }^{3}$, and W. W. Gregg ${ }^{4}$ \\ ${ }^{1}$ National Institute of Aquatic Resources, Denmark Technical University, Jægersborg Allé 1, 2920 Charlottenlund, Denmark \\ ${ }^{2}$ Plymouth Marine Laboratory, Plymouth, UK \\ ${ }^{3}$ Faculty of Environmental Earth Science, Hokkaido University, N10W5, Sapporo, 060-0810 Hokkaido, Japan \\ ${ }^{4}$ NASA Global Modeling and Assimilation Office, Greenbelt, MD, USA \\ Correspondence to: A. P. Palacz (arpa@aqua.dtu.dk)
}

Received: 24 April 2013 - Published in Biogeosciences Discuss.: 15 May 2013

Revised: 3 October 2013 - Accepted: 14 October 2013 - Published: 22 November 2013

\begin{abstract}
.
Modeling and monitoring plankton functional types (PFTs) is challenged by the insufficient amount of field measurements of ground truths in both plankton models and biooptical algorithms. In this study, we combine remote sensing data and a dynamic plankton model to simulate an ecologically sound spatial and temporal distribution of phytoPFTs. We apply an innovative ecological indicator approach to modeling PFTs and focus on resolving the question of diatom-coccolithophore coexistence in the subpolar highnitrate and low-chlorophyll regions. We choose an artificial neural network as our modeling framework because it has the potential to interpret complex nonlinear interactions governing complex adaptive systems, of which marine ecosystems are a prime example. Using ecological indicators that fulfill the criteria of measurability, sensitivity and specificity, we demonstrate that our diagnostic model correctly interprets some basic ecological rules similar to ones emerging from dynamic models. Our time series highlight a dynamic phyto-PFT community composition in all high-latitude areas and indicate seasonal coexistence of diatoms and coccolithophores. This observation, though consistent with in situ and remote sensing measurements, has so far not been captured by state-of-the-art dynamic models, which struggle to resolve this "paradox of the plankton". We conclude that an ecological indicator approach is useful for ecological modeling of phytoplankton and potentially higher trophic levels. Finally, we speculate that it could serve as a powerful
\end{abstract}

tool in advancing ecosystem-based management of marine resources.

\section{Introduction}

We are yet to obtain a consistent and complete view of the global biogeography of plankton functional types (PFTs), groups of organisms composed of many different species identified by a common biogeochemical function rather than a common phylogeny. We deal with the large uncertainty due to the insufficient amount of field measurements of ground truths in both plankton models (Anderson, 2005) and biooptical phytoplankton PFT algorithms (Brewin et al., 2011). Knowing how PFT distributions are changing is key to projecting biological responses to global climate change, in the geological past (Wells et al., 1999), present and future (Beaugrand et al., 2012; Bopp et al., 2005; Boyd and Doney, 2002). A requirement is to investigate regions such as the Southern Ocean, the subarctic North Pacific and the equatorial Pacific, the so-called high-nitrate, low-chlorophyll (HNLC) regions (Minas and Minas, 1992) where the ocean acts as a source of $\mathrm{CO}_{2}$ to the atmosphere (Takahashi et al., 2002) despite being sufficiently productive. According to modeling studies, these regions may also constitute PFT diversity hotspots (Prowe et al., 2012) or, to the contrary, PFT diversity deserts (Barton et al., 2010). 
A variety of recently developed phytoplankton size class (phyto-PSC) and phytoplankton PFT (phyto-PFT) biooptical algorithms may be used to monitor regional and global phytoplankton distributions at an intraseasonal resolution (Alvain et al., 2008; Bracher et al., 2009; Brewin et al., 2010; Hirata et al., 2011). Among the key phyto-PFTs are silicifiers (diatoms), whose biomass can be estimated from satellites (Sathyendranath et al., 2004; Alvain et al., 2008; Hirata et al., 2013), and calcifiers (coccolithophores), whose biomass estimates up until very recently (Sadeghi et al., 2012) were limited to bloom occurrence and area calculation (Alvain et al., 2008; Moore et al., 2012) and inference from particulate inorganic carbon (PIC) measurements (Balch et al., 2011). However, field measurements of biological processes, on the level of PFTs in particular, are not sufficiently resolved compared to chemical and physical properties of the ocean (Claustre et al., 2010). Thus, synoptic relationships between PFT biomass (derived from in situ phytoplankton cell and pigment abundance/biomass) and optical properties of the surface ocean (derived from remote sensing) cannot be constrained and evaluated consistently over all biogeochemical provinces. Borders between biogeochemical provinces shift dramatically on annual and longer scales (Boyd and Doney, 2002; Devred et al., 2007), challenging the integration of regional algorithms into global models (Cetinić et al., 2012).

Dynamic plankton models coupled to ocean circulation models take changing environmental conditions into account. Moreover, they derive PFT estimates from knowledge of the underlying mechanistic processes. However, whereas they can discern between several to tens of different groups (Follows et al., 2007), they struggle with the long-debated paradox of the plankton (Hutchinson, 1961). To our knowledge, none of the models operating on the PFT level can simulate the observed coexistence of more than one dominant group under limiting resources when their biogeochemical functions are similar yet need to be parameterized separately. For instance, fast-growing diatoms in the subarctic North Pacific and the Southern Ocean outcompete coccolithophores, preventing their biomass from building up (e.g., Gregg and Casey, 2007; Le Quéré et al., 2005; Sinha et al., 2010), in contrast to what remote sensing observations suggest (e.g., Alvain et al., 2008; Balch et al., 2011; Sadeghi et al., 2012). A PFT biogeochemical model is sensitive to the type of PFT classification, the choice of zooplankton grazing formulation (Hashioka et al., 2012) and, especially for diatoms and coccolithophores, the mixing formulation in the chosen physical model coupled to the plankton model (Sinha et al., 2010). The MARine Ecosystem Model Intercomparison Project (MAREMIP) (Hashioka et al., 2012) is currently examining the ability of these models to identify key processes and evaluate the role of functional groups in the whole ecosystem. Complementary to MAREMIP, the Satellite phyto-PFT Intercomparison Project (Hirata et al., 2012) is investigating the performance of satellite phyto-PFT models in the global ocean.

In a two-dimensional phytoplankton niche space defined by turbulence and nutrient concentration ("Margalef's mandala"), coccolithophores traditionally fall between diatoms, which thrive in well-mixed, high-nutrient regimes, and dinoflagellates, which dominate the stratified, lownutrient regimes (Margalef, 1978). Today we know that picoeukaryotic and prokaryotic autotrophs (e.g., Prochlorococcus, Synechococcus) successfully compete with dinoflagellates for their niche. Light is another important niche descriptor. Balch (2004) suggested that day length is as important as light intensity for the onset of coccolithophore (and likely other phyto-PFT) blooms, and should form the third dimension of phytoplankton mandala. The ability to locate phytoPFTs in their ecological niches allows us to derive ecological rules that can verify both plankton models and bio-optical algorithms. However, ecological rules can serve another purpose: they help identify key ecological indicators of change of PFTs - a task imposed by the rapidly changing climate.

Having acknowledged the challenges in monitoring and modeling biological processes explicitly, an ecological indicator approach is an alternative means of describing and managing marine ecosystems (e.g., Dale and Beyeler, 2001; Blanchard et al., 2010). In this study, we explore the possibility of applying an ecological indicator approach to simulate an ecologically consistent global distribution of phytoPFTs, with particular focus on diatoms and coccolithophores in the HNLC regions. We choose an artificial neural network (ANN) as our modeling framework because this artificial intelligence tool has the potential to interpret complex nonlinear interactions governing complex adaptive systems (Holland, 1995), of which marine ecosystems are a prime example (Levin, 1998). In order to enable projection of past and future phyto-PFT states, as well as their potential application in ecosystem management of marine resources (Palacz, 2012), we select ecological indicators that fulfill the criteria of indicators of good environmental status (GES) (Commission, 2008). These criteria, described by Link et al. (2010), include (i) measurability - the availability of data to estimate the indicator, (ii) sensitivity - the ability to detect change in an ecosystem, and (iii) specificity - the ability to link the said change in an indicator as a response to a known intervention or pressure.

The idea of using an ecological indicator approach to phyto-PFT modeling is not a new one. For instance, Raitsos et al. (2006) attempted to explain variability in North Atlantic blooms of coccolithophores by identifying their ecological indicators of change obtained from a combination of in situ, satellite and model data. Application of ANNs in the ecological approach to phyto-PFT modeling was pioneered by Raitsos et al. (2008), who estimated the probability of diatom occurrence in the North Atlantic from ecological (e.g., sea surface temperature, photosynthetically available radiation, surface chlorophyll $a$ concentration) and geographical 
(e.g., latitude, longitude) indicators. ANNs based on ecological indicators have also been used to simulate the distribution of $p \mathrm{CO}_{2}$ in the North Atlantic (Telszewski et al., 2009) and to compare patterns of biological production in eastern boundary upwelling regions (Lachkar and Gruber, 2012).

In contrast to these earlier studies, we attempt to use only ecological indicators to simultaneously model biomass distribution of four phyto-PFTs in key biogeochemical provinces, including the open-ocean HNLC regions. We hypothesize that our phyto-PFT ecological indicator model (hereafter PhytoANN) will

- interpret the complex nonlinear interactions between four phyto-PFTs and their ecological indicators in a variety of distinct biogeochemical conditions, and

- improve the existing model estimates of monthly climatology and time series distribution of diatoms and coccolithophores in the HNLC regions.

\section{Methods}

\subsection{Source of indicators}

We selected the following ecological indicators as principal inputs into the PhytoANN model: (i) sea surface temperature (SST), (ii) wind speed (Wspd), (iii) photosynthetically available radiation (PAR), (iv) surface chlorophyll $a$ concentration (Chl) and (v) mixed layer depth (MLD). Although we considered two additional indicators, modeled surface nitrate $\left(\mathrm{NO}_{3}\right)$ and surface iron $(\mathrm{Fe})$ concentration, we did not include them in the final PhytoANN because they displayed significant bias with respect to observations in several biogeographic provinces, and they did not add significantly towards explaining patterns of phyto-PFT variability. We assume that changes in $\mathrm{NO}_{3}$ distribution can largely be explained by associated changes in SST and Chl. This assumption has been used to derive a $\mathrm{NO}_{3}$ index (Nelson et al., 2004) and $\mathrm{NO}_{3}$ maps from satellite data alone (Silió-Calzada et al., 2008).

We opted to purposefully omit geographical and time indicators in this study because of two main reasons. Firstly, these indicators do not meet the specificity and sensitivity criteria of Link et al. (2010) and go against the philosophy of our ecological indicator model. Including geographical information and time, which had a strong weight in the model used by Raitsos et al. (2008), could prevent the model from capturing any geographical or phenological shifts, as instead of the PFTs reacting mainly to changes in the environmental conditions at a specific location, the model would just predict the phyto-PFTs based on the typical (climatological) cycles at that specific location, estimated from latitude, longitude and time. Secondly, using these inputs would prevent us from applying the model outside of the latitude and longitude range included in the training domain.
SST data came from NOAA's optimum interpolation version 2 product (NOAA-OI-SST-V2) provided by the NOAA/OAR/ESRL PSD in Boulder, Colorado, USA (http://www.esrl.noaa.gov/psd/). Wspd data were downloaded from NOAA Ocean Winds (http://www.ncdc.noaa.gov/oa/rsad/air-sea/seawinds.html).

The wind speeds were generated by blending observations from multiple satellites. Zhang et al. (2006) describe the details of the Wspd algorithm. PAR and Chl data came from the Sea-viewing Wide Field-of-view Sensor (SeaWiFS). We downloaded the processed and gridded (monthly, $9 \mathrm{~km} \times 9 \mathrm{~km}$ ) data from National Aeronautics and Space Administration (NASA) Ocean Productivity project (http://orca.science.oregonstate.edu/1080.by.2160.monthly. hdf.par.seawifs.php and http://orca.science.oregonstate.edu/ 1080.by.2160.monthly.hdf.chl.seawifs.php). Information about MLD came from the multiyear Simple Ocean Data Assimilation (SODA) model (Carton and Giese, 2008), which attempts to reconstruct the changing physical climate of the global ocean based on a sequential data assimilation approach. A forecast of MLD was derived from the forecast density fields based on a 0.125 potential density criterion (following e.g., Kara et al., 2003). We obtained the processed and gridded data (monthly, $9 \mathrm{~km} \times 9 \mathrm{~km}$ ) also from NASA Ocean Productivity (http://orca.science. oregonstate.edu/1080.by.2160.monthly.hdf.mld.soda.php).

We used monthly, $1^{\circ} \times 1^{\circ}$ data from 1997-2004 time series. Details are included in the appendix Table A1.

\subsection{Source of phyto-PFTs}

We chose to model four phyto-PFTs: (i) diatoms, (ii) coccolithophores, (iii) cyanobacteria and (iv) chlorophytes. In order to train the PhytoANN model to associate phyto-PFT biomass with environmental conditions, we obtained biomass estimates from NASA Ocean Biogeochemical Model (NOBM) (Gregg et al., 2003). Processed and gridded (monthly, $1^{\circ} \times 1^{\circ}$ ) data were downloaded from NASA's Giovanni (http://gdata1.sci.gsfc.nasa.gov/daac-bin/ G3/gui.cgi?instance_id=ocean_model). NOBM is a coupled three-dimensional general circulation, biogeochemical and radiative model of the global oceans that assimilates SeaWiFS chlorophyll $a$. It was validated using data from in situ (Joint Global Ocean Flux Study (JGOFS)) and satellite data sources (SeaWiFS and MODIS Ocean Color instruments). Biogeochemical processes in the model were controlled by factors such as circulation and turbulence dynamics, irradiance availability and the interactions among four phytoplankton functional groups (diatoms, chlorophytes, cyanobacteria and coccolithophores), four nutrients (nitrate, ammonium, silica and dissolved iron) and one herbivore group (Gregg et al., 2003). The model architecture is fully described in Gregg (2000) and Gregg (2002). In this model, chlorophytes were intended to represent prasinophytes, pelagophytes and other flagellates. Cyanobacteria were meant to encompass 


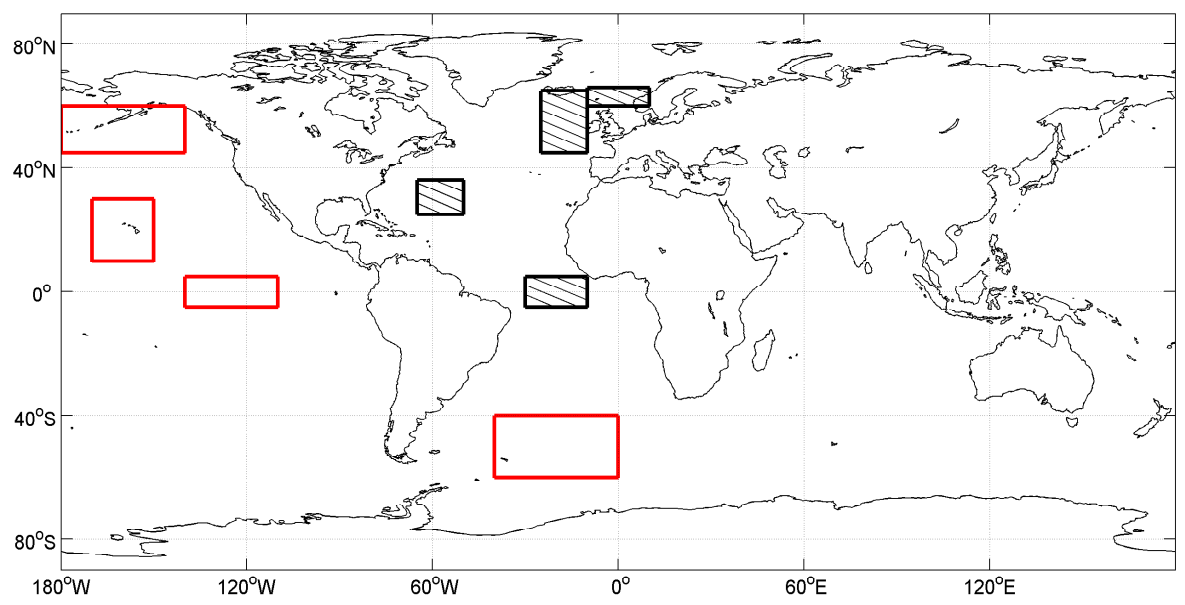

Fig. 1. Location of the areas used for both confirmatory and exploratory analysis (black) and only exploratory analysis (red). Black boxes correspond to the NorwSea, NEAtl, WCAtl and EqAtl when looking from north to south. Red boxes correspond to the NEPac, CPac, EEP and AntAtl when looking from north to south.

all pico-prokaryotes. NOBM phyto-PFT results have been thoroughly evaluated against in situ and satellite estimates in Gregg and Casey (2007).

The choice of NOBM model data used for training the PhytoANN was dictated by two factors. First, there are not enough in situ data at a sufficient spatial and temporal resolution that is sampled from the necessary range of biogeochemical provinces. This is despite of the fact that a global atlas of PFT biomass measurements has now been assembled by the MAREDAT project (Smith and Pesant, 2012). Unfortunately, its coverage of diatom (Leblanc et al., 2012) and coccolithophore (O'Brien et al., 2012) measurements is not enough to produce complete monthly climatology maps beyond the northeast Atlantic. Second, only by training the PhytoANN on other model phyto-PFT results can we later directly compare two model outputs to independent phyto-PFT estimates within and outside of the training domain. We can verify the second hypothesis of our study because the PhytoANN is not trained on any NOBM results that have a strong bias in phyto-PFT biomass. Therefore, PhytoANN's diatom biomass projection in HNLC regions for example is not at all influenced by NOBM's overestimated diatom biomass in these regions.

Additional independent phyto-PFT estimates come from in situ and remote sensing observations. We used the same set of JGOFS in situ data as Gregg and Casey (2007), assuming that differences in borders of their biogeographic provinces and our regions of interest are small enough to allow for such comparison. Where available, we referred to new data, for example from the Equatorial Biocomplexity cruises in the eastern equatorial Pacific (Taylor et al., 2011).

Remote sensing phyto-PFT biomass estimates came from a bio-optical algorithm (Hirata et al., 2011, 2013). This algorithm established error-quantified, synoptic-scale relationships between SeaWiFS Chl and 10 phytoplankton pig- ment groups at the sea surface to determine phyto-PSC and phyto-PFT estimates. Phyto-PFTs include diatoms, dinoflagellates, green algae, prymnesiophytes (haptophytes), pico-eukaryotes, prokaryotes and Prochlorococcus sp., while phyto-PSCs include micro-, nano- and picoplankton. An earlier version of the PSC component (Hirata et al., 2008) was recently evaluated through a global intercomparison of such algorithms (Brewin et al., 2011).

Remote sensing estimates of PIC concentration may be used to discern regional patterns of seasonal to interannual variability in coccolithophore biomass. PIC data were derived using a two-band algorithm based on normalized water-leaving radiance at 440 and $550 \mathrm{~nm}$ (Balch, 2005). Though not directly correlated to living coccolithophore biomass, PIC was established as a good proxy for monitoring changes in the distribution of this PFT (e.g., Balch et al., 2011; Moore et al., 2012). Data were downloaded from the NASA Giovanni portal.

\subsection{Spatial and temporal domains}

Figure 1 shows the geographical extent of the areas used for training and evaluation (confirmatory analysis) and projection of new states (exploratory analysis). Four Atlantic regions, corresponding to the northeast Atlantic Ocean (NEAtl), the Norwegian Sea (NorwSea), the western central Atlantic Ocean (WCAtl) and the equatorial Atlantic Ocean (EqAtl), were included in both the confirmatory and exploratory part of the analysis. These areas were selected for training because (i) together they provided a very wide geographical and seasonal range of input and target values sufficient to make the PhytoANN sensitive to most biogeochemical conditions, and (ii) their NOBM PFT biomass estimates were in general in very good agreement with observations available from the Atlantic Basin (Gregg and Casey, 2007). 


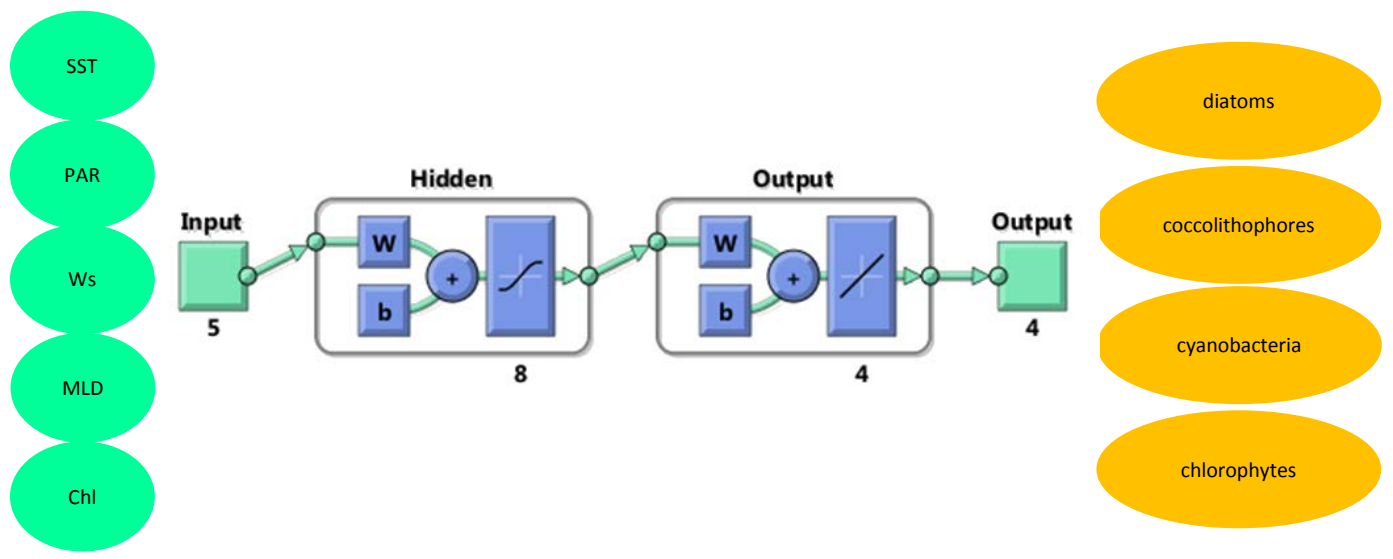

Fig. 2. A conceptual model illustrating how the ANN interprets the relationship between 5 (green circles), input variables, as well as between input and 4 target variables (yellow circles). Each hidden neuron in layer 1 computes the sum of input values multiplied by connection weights (w) and a bias term (b), and calculates the activation value of each neuron (being a nonlinear sum of all inputs). Each output neuron in layer 2 is a linear sum of the activation values from all layer 1 neurons multiplied by respective connection weights and a bias term.

We used a total of 87000 data points from the selected training regions. Regions used exclusively for exploratory analysis included the eastern equatorial Pacific Ocean (EEP), the central subtropical Pacific Ocean (CPac), the subarctic northeast Pacific Ocean (NEPac) and the Antarctic Atlantic Ocean (AntAtl). From the Appendix Table A2 we can see that none of the input values used for exploratory analysis exceeds the range used during training. This means that chosen training regions are ecologically representative also of the conditions observed in HNLC regions. Details of spatial and temporal resolution of data are included in the Appendix Table A1.

\subsection{PhytoANN training and evaluation}

In this study we use a basic feedforward ANN that contains inputs, outputs and one hidden and one output layer fully connected via ANN's free parameters (weights and biases) as illustrated in Fig. 2. The feedforward structure means that there is a unidirectional flow of information without feedback from the output back to the input layer. We use supervised learning to train the ANN to interpret complex and nonlinear relationships between ecological indicators (inputs) and phyto-PFT biomass (targets) by iteratively introducing a number of input-output example sets. We carry out the training using a common back-propagation (BP) algorithm that involves the forward and backward phase. During the first phase, free parameters of the network are fixed, and the input signal is propagated through the network layer by layer (Fig. 2). The activation value of each processing unit, called a neuron, is determined by the sum of inputs multiplied by the connection weight. The forward phase finishes with the computation of an error term being the difference between the generated output and the known target. During the backward phase, the error term is propagated through the ANN in the backward direction. It is during this phase that adjust- ments are applied to weights and biases of the network so as to minimize the error term according to the mean-squared error (MSE) criterion. The adjustment of these free parameters is performed according to the gradient descent rule. The described procedure is common for many ecological applications of ANNs (Lek and Guegan, 1999). We use the Mathworks MATLAB ANN toolbox to perform all calculations.

Model training and evaluation is described in great detail in Appendix A. Here, we describe the entire procedure with consecutive steps from data selection and processing to PhytoANN model development and its application:

1. Select ecological indicators that fulfill the criteria of Link et al. (2010).

2. Assemble a matrix of input and target data and place them on a unified spatial and temporal grid.

3. Divide all available data between confirmatory and exploratory data sets.

4. Inspect histograms of individual input and target data, and transform them onto a log-10 scale if their distribution is non-normal.

5. Normalize all processed input and target data onto a common minimum-maximum range (e.g., -1 to 1) in order to avoid bias towards high-value inputs/outputs.

6. Divide the confirmatory data set into training (70\%), testing (15\%) and evaluation (15\%) subsets, either randomly or systematically.

7. Set up a feedforward ANN with one input, one hidden layer and one output layer. 

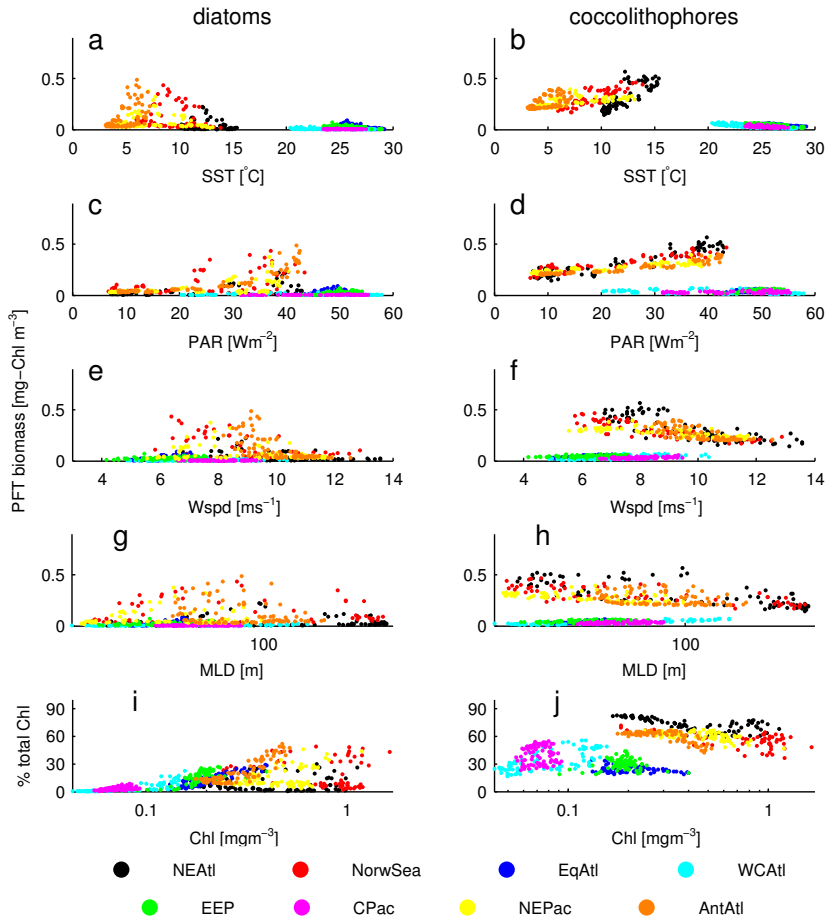

Fig. 3. Scatter plots showing the emerging relationship between PhytoANN diatom (left column) and coccolithophore (right column) biomass $\left[\mathrm{mg} \mathrm{Chl} \mathrm{m}^{-3}\right](\mathbf{a}-\mathbf{h})$ or $\%$ of total Chl $(\mathbf{i}, \mathbf{j})$ vs. individual ecological indicators color coded according to domain of origin. On the $x$ axis from top to bottom: SST, PAR, Wspd, MLD and Chl. All data points come from exploratory analysis only, and thus they are box-average and monthly average estimates from October 1997 to December 2004.

8. Select the type of transfer, performance and training function, and initial ANN parameters. Initialize connection weights and biases randomly within the network.

9. Train the network with early stopping.

10. Evaluate ANN performance within confirmatory regions by calculating error statistics.

11. Perform sensitivity analysis on key parameters listed above and retrain the ANN to maximize performance.

12. Apply a total of 10 trained nets to time series from exploratory regions to obtain ensemble mean results.

13. Normalize phyto-PFT biomass with respect to total $\mathrm{Chl}$ to assure conservation of $\mathrm{Chl}$ biomass.

14. Compare the ensemble mean output with target as well as independent data.
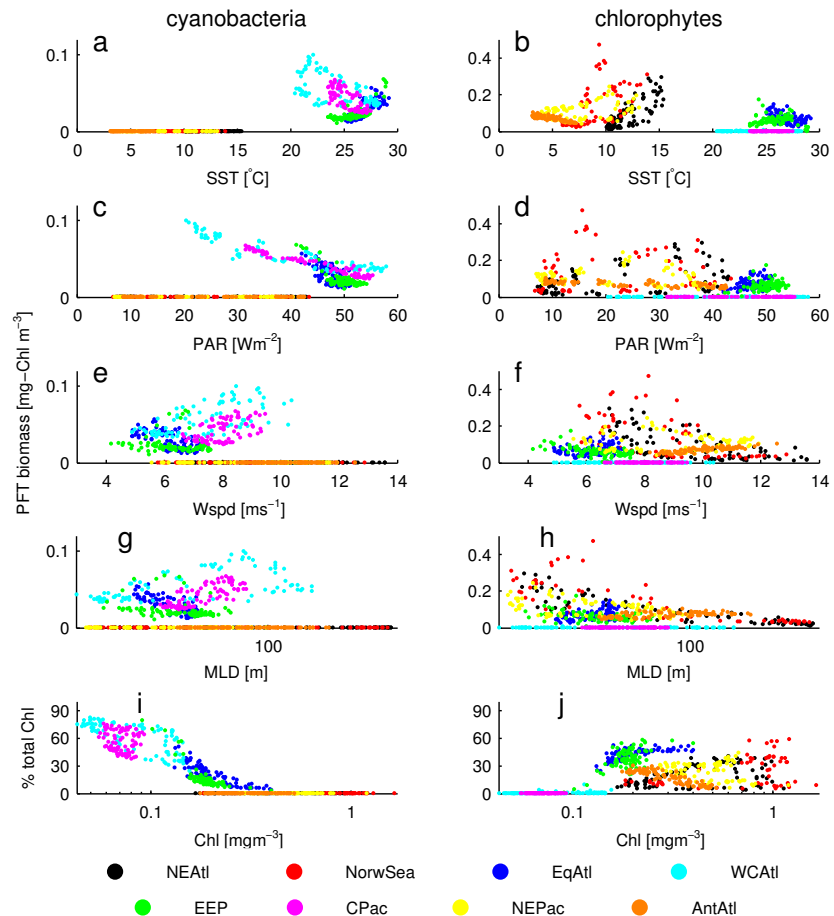

Fig. 4. Scatter plots showing the emerging relationship between PhytoANN cyanobacteria (left column) and chlorophyte (right column) biomass $\left[\mathrm{mg} \mathrm{Chl} \mathrm{m}^{-3}\right](\mathbf{a}-\mathbf{h})$ or $\%$ of total Chl $(\mathbf{i}, \mathbf{j})$ vs. individual ecological indicators color coded according to domain of origin. On the $x$ axis from top to bottom: SST, PAR, Wspd, MLD and Chl. All data points come from exploratory analysis only, and thus they are box average and monthly average estimates from October 1997 to December 2004.

\section{Results and discussion}

\subsection{Ecological niches of PFTs}

The first aim is to investigate how the PhytoANN interprets the interactions between PFTs and their environmental indicators. We break down the problem into four questions here. Which interactions are linear and which nonlinear? How do the interpretations vary across PFTs? Does the model capture the same relationships that are described mathematically by the NOBM that was used to train it? How are the weights distributed among the interactions?

We answer the first three questions using information presented in Figs. 3 and 4. By plotting PhytoANN estimates of phyto-PFT biomass against an observed range of one input at a time, we detect very nonlinear relationships in all cases, and for all phyto-PFTs. However, some linear patterns emerge after we separate the results according to the spatial domain of origin. Consequently, we notice two distinct physical and/or biogeochemical regimes that can be separated into high- and low-latitude regions. All four phyto-PFTs exhibit similar responses to conditions in the NEAtl, NorwSea, NEPac and 
AntAtl (hereafter HighLat regime), but very different types of responses to conditions in the EqAtl, EEP, WCAtl and $\mathrm{CPac}$ (hereafter LowLat regime). In general, HighLat regime is characterized by relatively lower SST and lower PAR but higher Wspd and Chl compared to the LowLat regime.

Within a single regime, phyto-PFT biomass shows stronger relationships to individual inputs. For example, coccolithopore biomass is positively correlated with PAR in the HighLat regime (Fig. 3d), and cyanobacteria biomass is highly correlated with PAR in the LowLat regime (Fig. 4c). Compared to coccolithopores and cyanobacteria, diatoms and chlorophytes exhibit little if any visible relationship with individual indicators, except with Chl. We observe characteristic relationships between $\mathrm{Chl}$ and all phyto-PFTs contribution to total $\mathrm{Chl}[\%]$, which are in agreement with patterns of covariability between $\mathrm{Chl}$ and phyto-PFT contribution [\%] derived for bio-optical algorithms (Hirata et al., 2011). Hirata et al. (2011) concluded that $\mathrm{Chl}$ is not only an index of phytoplankton biomass but also an index of phytoplankton community structure at the synoptic scale. In the case of diatoms, we note a mean exponential increase in percentage of total $\mathrm{Chl}$ as a function of $\log 10$ of Chl. Our spectrum differs from Hirata et al. (2011) in that there is a larger scatter around the main trend towards the high-Chl concentration end. This scatter is associated with lower diatom contributions found in the NEAtl, NorwSea and partially also the NEPac (Fig. 3i). Comparing the contribution of PhytoANN coccolithophores with haptophytes from the bio-optical model, the relationship differs at the higher end of the Chl range. The PhytoANN estimates that coccolithophores make up a greater proportion of total Chl under bloom conditions observed in the subarctic regions (Fig. 3j). This comparison should be viewed with caution because coccolithopores constitute only a fraction of the larger haptophyte phyto-PFT group considered by Hirata et al. (2011).

When comparing percentage of total $\mathrm{Chl}$ in cyanobacteria in the PhytoANN (Fig. 4i) with Prochlorococcus in the bio-optical model (Hirata et al., 2011, their Fig. 2i), we see that maximum percentage contribution is associated with low total Chl in both models. Although the shapes of the two distributions along the $\mathrm{Chl}$ gradient are very similar, there are some differences in the magnitude of fractional contribution at lowest $\mathrm{Chl}$ values. However, this difference would be minimal if we assumed that in the NOBM (and thus in the PhytoANN) the broad cyanobacteria group overlaps not only with Prochlorococcus but partially also with prokaryotes classified separately in the bio-optical model (Hirata et al., 2011, their Fig. 2g).

Chlorophytes are perhaps most difficult to evaluate because they should to some extent functionally resemble more than one group in the bio-optical algorithm. In the PhytoANN, chlorophytes contribute the most to total $\mathrm{Chl}$ under moderate Chl levels (Fig. 4j). Such a pattern is in general close to that of green algae in the bio-optical algorithm (Hirata et al., 2011, their Fig. 2h). The only clear discrepancy occurs for the NorwSea region, where the PhytoANN predicts very high percentage contribution of chlorophytes even for the highest $\mathrm{Chl}$ values. The comparisons with the biooptical model therefore suggest that the PhytoANN overestimates the contribution to total $\mathrm{Chl}$ of both coccolithophores and chlorophytes in the North Atlantic Basin.

It is interesting to compare PhytoANN relationships with those in the NOBM (Figs. B1 and B2). In general, we see that the PhytoANN was able to capture the same general relationships described mechanistically by the NOBM. Considering that NOBM's physical model is partially forced with similar sources of data as used for indicators of change in the PhytoANN (e.g., SST, wind stress), this result need not be surprising and may suggest that our derived relationships are artifacts of the empirical or mechanistic relationships in the NOBM. Nevertheless, we observe important differences in how phyto-PFTs are distributed along environmental gradients in the two models, especially in areas modeled only during exploratory analysis. The most striking difference is that in the NOBM, NEPac and AntAtl coccolithophores seem to fall into a separate environmental regime, unlike in the PhytoANN. In the NOBM, coccolithophores are poorly correlated with SST, PAR, Wspd and MLD in those regions. Consequently, their large percentage contribution to total $\mathrm{Chl}$ is also not associated with high $\mathrm{Chl}$ concentration there. This analysis confirms what was previously described by Gregg and Casey (2007), namely that the NOBM does not predict coccolithophore blooms coincident with high diatom biomass concentrations anywhere outside of the nutrientreplete North Atlantic Basin.

The results of this analysis also describe the ecological niches of individual phyto-PFTs that can be compared to the traditional phytoplankton mandala. In the PhytoANN, diatom blooms occur under SST between 5 and $15^{\circ} \mathrm{C}$, PAR between 20 and $45 \mathrm{~W} \mathrm{~m}^{-2}$, Wspd between 5 and $10 \mathrm{~m} \mathrm{~s}^{-1}$, and $\mathrm{Chl}$ above $0.25 \mathrm{mg} \mathrm{m}^{-3}$. Coccolithophores are in general more abundant under low mixing (shallower MLD) regimes - consistent with what we know of their ecology (Balch, 2004). Still, they occupy a similar niche to diatoms. Their biogeographical extent is thus considerably greater than in the NOBM (Gregg and Casey, 2007) or another global dynamic PFT model - PlankTOM (Sinha et al., 2010). Highlatitude blooms predicted by PhytoANN both in the Atlantic and the Pacific are in agreement with in situ and remote sensing coccolithophore estimates in surface waters, as well as with geological records of coccoliths in bottom sediments (Balch, 2004, and references therein). Cyanobacteria and chlorophytes dominate the LowLat regime, which in general can be described by high SST, high PAR, low Wspd and shallow MLD conditions. Their ecological niche is consistent with Margalef's mandala and numerous field studies that concluded that the intensity of surface blooms of cyanobacteria is regulated by a combination of climatic factors, such as water temperature, solar radiation, and wind speed (Stal et al., 2003; Whitton and Potts, 2000). 


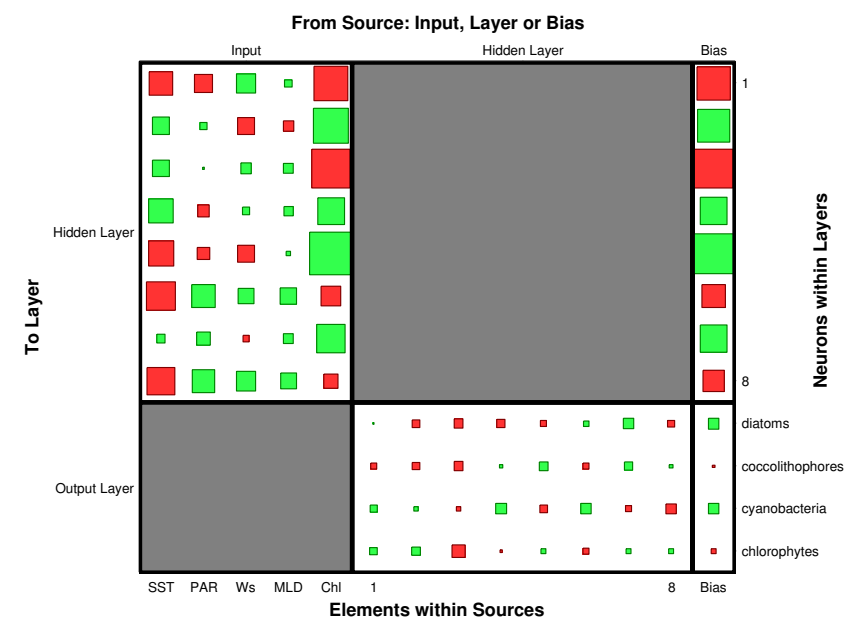

Fig. 5. Hinton-weight diagram depicting relative weights assigned to all connections within 1 of 10 PhytoANNs used to create the ensemble. Green corresponds to positive correlation, red to negative correlation. The area of the square is proportional to the strength of correlation. The left-hand side illustrates the connection weights between the input and the hidden layer. The right-hand side illustrates the connection weights between the hidden layer and the output layer.

Results from Figs. 3 and 4 also indicate the role of interactions between two or more indicators. For example, under the same levels of PAR, there is large buildup of cyanobacteria biomass in the LowLat regime but no such buildup in the HighLat. This is clearly because of coinciding differences in SST but likely also variable Wspd and MLD conditions (Fig. 4). Of course these interactions are well known and appear also in the NOBM (Figs. B1 and B2). Yet it is important to note that the PhytoANN is capable of interpreting these complex and often nonlinear interactions between phyto-PFTs and their ecological indicators because it enables us to verify the first hypothesis of this study.

In order to now say what is the distribution of weights assigned to these interactions, we use a Hinton diagram from 1 of 10 PhytoANNs used to form the ensemble. In Fig. 5 we see that Chl, SST, PAR and Wspd are strongly correlated within a single neuron. MLD appears to be the least significant indicator on its own (but could be significant in combination with others). While it may often be closely associated with Wspd, it can also have an opposite sign assigned, as in the fifth and seventh neuron. We note that in this net, only the sixth and eighth neurons store very similar information about the interactions between inputs. In most other nets included in the ensemble, all eight neurons provide unique information. With respect to connections from the hidden layer to the output later, sign and strength of correlations differ from one neuron to another. Note that any one neuron may store important information about one or two PFTs but at the same time provide insignificant information about the remaining

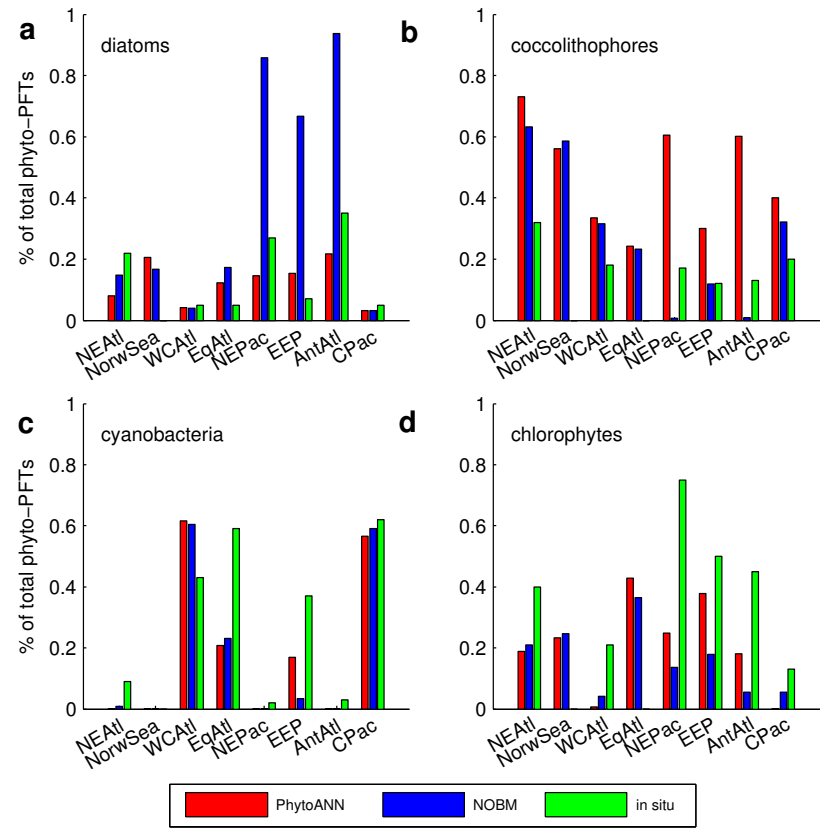

Fig. 6. Approximate box or basin-average comparison between the 1997-2004 annual mean percentage contribution to total Chl biomass of (a) diatoms, (b) coccolithophores, (c) cyanobacteria and (d) chlorophytes according to NOBM (blue), PhytoANN (red) and in situ (green) estimates. In situ estimates were derived from both $\mathrm{C}$ - and Chl-based measurements. Here, estimates were derived from a combination of data collected by Gregg et al. (2003) (http://gmao. gsfc.nasa.gov/research/oceanbiology/data.php) and EEP data from Taylor et al. (2011, their Table 3).

phyto-PFTs. This indicates a rather unique phyto-PFT response to various combinations of environmental conditions interpreted by the PhytoANN.

\subsection{Annual average phytoplankton community composition}

The relationship between phyto-PFTs and ecological indicators also reveals important regional differences in phytoplankton community composition. In Fig. 6 we compare NOBM and PhytoANN annual mean relative contribution to total $\mathrm{Chl}$ biomass and relate it to some available field estimates. In diatoms, we note that PhytoANN's estimates are in line with those of NOBM in areas where NOBM was used for training. However, significant differences are noted elsewhere. In the NEPac and the AntAtl, PhytoANN predicts less than $20 \%$ annual contribution of diatoms, which is much closer to observations compared to NOBM (Fig. 6). In the EEP, although PhytoANN estimates a much smaller diatom contribution relative to NOBM (18 vs. $65 \%$ ), it is still twice as high as the less than $10 \%$ observed contribution. 


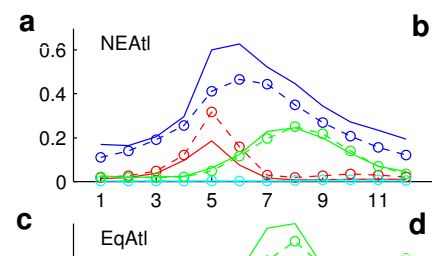

b 0.6 NorwSea
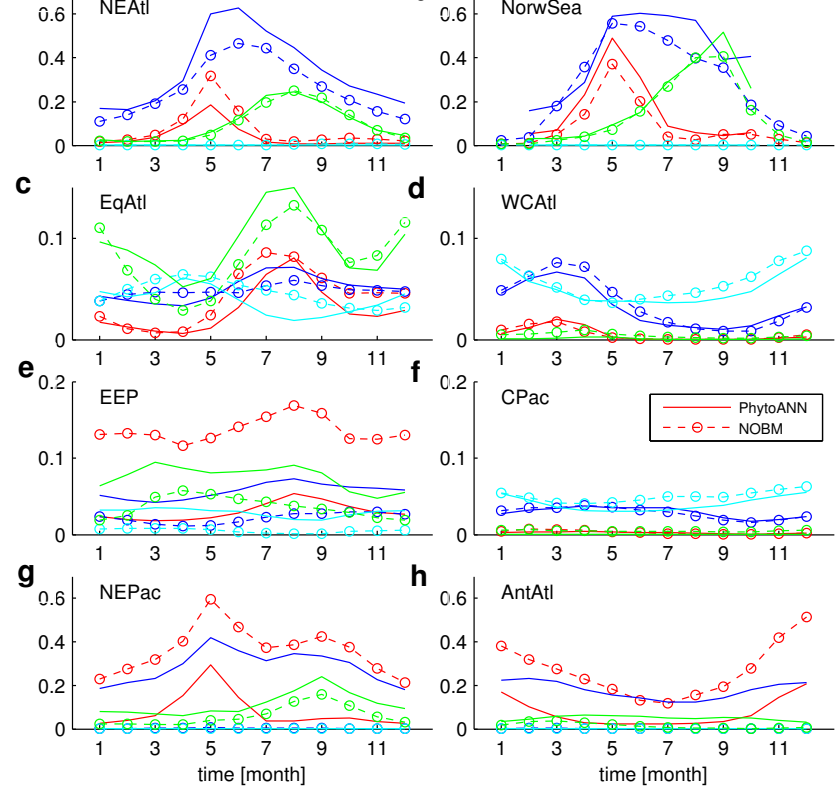

(1.6) AntAtl
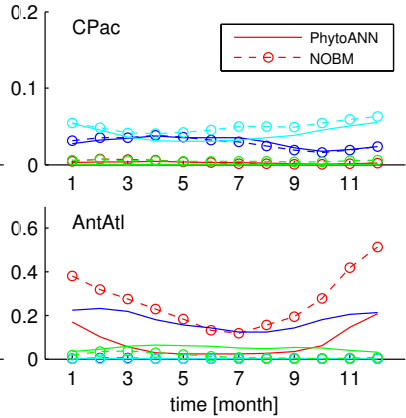

Fig. 7. 1997-2004 monthly climatology of NOBM (dashed lines with open circles) and PhytoANN (solid lines) phyto-PFT biomass estimates from confirmatory (a NEAtl, b NorwSea, c EqAtl, d WCAtl) and exploratory areas (e EEP, f CPac, g NEPac, h AntAtl). Each plot includes four PFTs: diatoms (red), coccolithophores (blue), chlorophytes (green) and cyanobacteria (cyan). All phytoPFT biomass in units of $\mathrm{mg} \mathrm{Chlm} \mathrm{m}^{-3}$.

In NOBM, high diatom contribution is almost always at the expense of severely underestimating coccolithophores. This is in contrast to PhytoANN, which in the NEPac and AntAtl predicts their $60 \%$ contribution compared to almost $0 \%$ in the NOBM (Fig. 6). It should be noted that NOBM appears to overestimate coccolithophore contribution in two out of four regions used to train the PhytoANN (with two others not evaluated against observations). Hence, it is expected that the PhytoANN overestimates coccolithophores in those and other regions as well (e.g., EEP, NEPac and AntAtl). Nevertheless, the fact that PhytoANN predicts a significant contribution of coccolithophores suggests the existence of suitable ecological niches for coccolithophores in the NEPac and AntAtl, as well as in the EEP.

Similarity of ecological niches of the NEAtl, NEPac and AntAtl are evident both in PhytoANN and NOBM. For example, both models rely on a similar total $\mathrm{Chl}$, which is not surprising considering that NOBM assimilates SeaWiFS Chl during its simulation. Therefore, the main difference between the model phyto-PFT distributions in these regions originates primarily from distinct partitioning of $\mathrm{Chl}$ between the phyto-PFTs. In NOBM it depends on nutrient uptake and light availability in a dynamical context, while in PhytoANN it depends on the sum of favorabilities of these and other environmental conditions.
As for cyanobacteria, the largest difference between the two models is observed in the EEP (Fig. 6). Here, higher biomass estimates from PhytoANN are closer but still significantly lower than observed. On the other hand, though similar to NOBM, PhytoANN biomass estimate is much too low in the EqAtl relative to observations. This is likely the cause of its underestimate in the ecologically similar EEP. In the WCAtl box, both models predict a proportion of cyanobacteria biomass that is higher than reported from the Bermuda Atlantic Time Series (BATS) (Lomas and Bates, 2004).

In general, both NOBM and PhytoANN struggle to reflect the observed contribution of chlorophytes to total phytoplankton biomass (Fig. 6). We note that NOBM underestimates their contribution in the NEAtl and the WCAtl - regions used to train PhytoANN. We had no available data to compare chlorophytes specifically in the NorwSea and the EqAtl. As for the exploratory regions, PhytoANN projects chlorophyte biomass levels in better agreement with observations. Nevertheless, it underestimates their contribution in the EEP, the AntAtl and the NEPac. In the CPac, contrary to NOBM, it is actually not capable of simulating any chlorophytes. This is likely related to the fact that PhytoANN's training fit is lowest in the WCAtl, which is also ecologically most similar to the $\mathrm{CPac}$.

\subsection{Seasonal succession of phyto-PFTs}

How do these ecologically driven predictions of phyto-PFT distributions affect what we know about seasonal succession of phytoplankton in these selected regions? In Fig. 7a-d we see that our model can reproduce the monthly climatologies of NOBM phyto-PFTs very well in regions used for training. In the two adjacent boxes of NEAtl and NorwSea, coccolithophores increase substantially in biomass during the spring bloom and become by far the most dominant group by summer time. The spring phytoplankton bloom also shows a large increase in diatom biomass, both in the NOBM and PhytoANN. Chlorophytes make up the most of the smaller fall bloom, while cyanobacteria constitute an insignificant part of the community. Coccolithophores reach their peak in June, which is in agreement with field measurements of Emiliania huxleyi blooms (Fernandez et al., 1993; Raitsos et al., 2006) and remote sensing PIC estimates (Balch, 2004) (Fig. 8a). The timing of the peak of the large spring (April) and smaller fall diatom bloom (October) match well with field studies (Edwards and Richardson, 2004; Barton et al., 2013) but also with estimates from the bio-optical model of Hirata et al. (2011) (Fig. 8a). As expected, the fall bloom, centered around August and September, is mostly made up of chlorophytes. This is also in agreement with long-term observations at these latitudes (Edwards and Richardson, 2004; Barton et al., 2013). The seasonally changing ratio of diatoms to dinoflagellates is thus well represented in the PhytoANN, and is similar to NOBM results (Fig. 8a) and in situ data (Leterme et al., 2005). 
PhytoANN predicts that coccolithophore biomass is higher than that of diatoms, even at the peak of the spring phytoplankton bloom. Even though coccolithophore blooms are very abundant in the North Atlantic, especially southwest of Iceland and in the Norwegian Sea, the model is likely to overestimate their contribution here, especially in the spring. In the NorwSea, the bio-optical model of Hirata et al. (2011) shows haptophyte biomass lower than that of diatoms during the March-June period (Fig. 8a). On the other hand, the most recently improved PhytoDOAS bio-optical algorithm predicts spring and summer coccolithophore biomass as high as in NOBM and PhytoANN (Sadeghi et al., 2012, their Fig. 7). The summer peak in coccolithophore biomass is also seen in the PIC time series (Fig. 8a). However, the distribution is much narrower around the June peak compared to NOBM and PhytoANN. It also shows a more pronounced decline in biomass in late summer and early fall. Alvain et al. (2008) analyzed monthly climatology results from their bio-optical PHYSAT diagnostic model in the North Atlantic box $\left(40-70^{\circ} \mathrm{N}, 60-20^{\circ} \mathrm{W}\right)$ which has a similar latitudinal extent to our NEAtl box. They concluded that diatoms contribute only at most $20 \%$ of total Chl during the spring phytoplankton bloom (their Fig. 8). This does not mean, however, that the remaining $80 \%$ from nanoeukaryotes explains the really high proportion of coccolithophores in the PhytoANN. One reason for coccolithophore overestimation in the NEAtl and NorwSea might be the fact that both NOBM (Fig. B1j) and PhytoANN (Fig. 3j) associated coccolithophore outbursts with highest $\mathrm{Chl}$ values. This is in contrast to the findings of Fernandez et al. (1993), who reported a huge coccolithophore bloom characterized by high PIC levels but relatively low Chl (less than $1 \mathrm{mg} \mathrm{m}^{-3}$ ) and particulate organic carbon concentrations. It is possible that modeling calcifier biomass in general should not be based on units of Chl.

It is noteworthy that the distribution of coccolithophores and diatoms even in a 3-month average satellite image is extremely patchy (Sadeghi et al., 2012). Patchiness in phytoPFT distributions suggests some spatial variability in ecological niches within the North Atlantic biogeochemical domain. Probability of diatom occurrence modeled by Raitsos et al. (2008) also varied greatly across the basin even during a 1-week snapshot image. The recent North Atlantic Bloom Experiment (NABE) in 2008 confirmed the extreme patchiness in patterns of biological productivity, phytoplankton species composition and associated carbon fluxes in this region (Alkire et al., 2012; Mahadevan et al., 2012). The relatively coarse resolution of NOBM data used in this study does not resolve the effects of this patchiness. We are currently testing the hypothesis that, given a higher spatial and temporal resolution of inputs, PhytoANN might generate a more complex image of phyto-PFT biogeography in response to a dynamic physical and biogeochemical environment. The purpose of this study, however, is to evaluate the
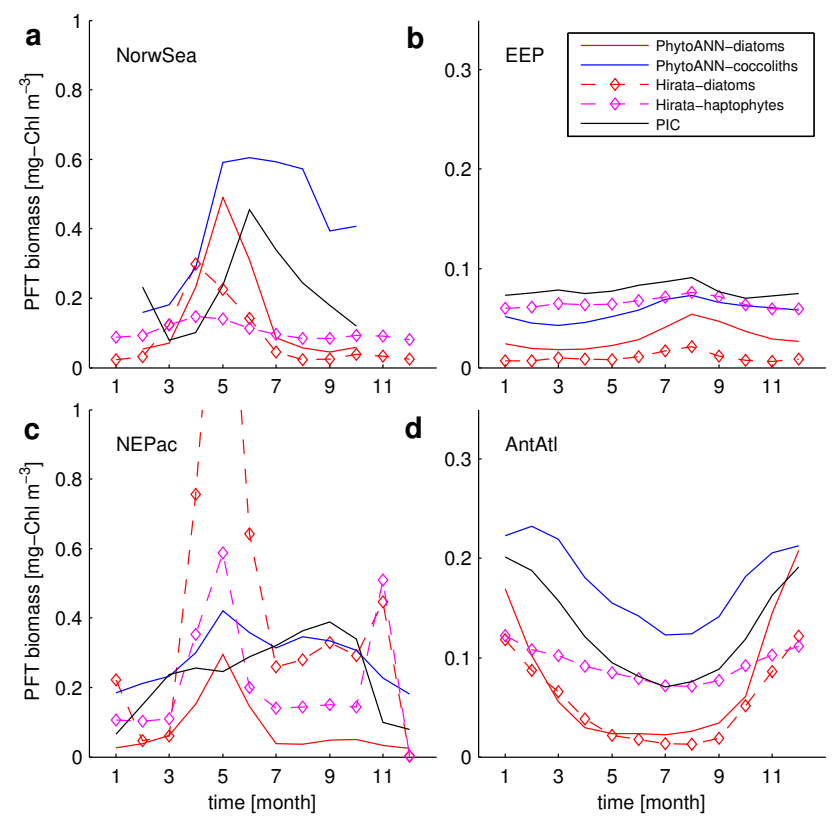

Fig. 8. 1997-2004 monthly climatology of diatom (red) and coccolithopore (blue) biomass from PhytoANN compared with diatoms and haptophytes (magenta) from the bio-optical algorithm as well as PIC from space (black) in four areas: (a) NorwSea, (b) EEP, (c) NEPac and (d) AntAtl. PhytoANN and PIC results are marked with a solid line, while the bio-optical algorithm with a dashed line. PIC values in mol $\mathrm{Cm}^{-3}$ were multiplied by an arbitrary factor of 300 to match scales.

performance of our novel approach only in terms of domainaveraged monthly climatologies of four phyto-PFTs.

In the absence of strong seasonality in the EqAtl, the most pronounced feature is the summer to early fall increase in diatoms and chlorophytes (Fig. 7c). Coccolithophores show little annual variability, and cyanobacteria remain at an almost constant biomass level. Here, PhytoANN results match those of NOBM very well. Minimum discrepancies in the timing of the maximum phyto-PFT biomass are insignificant considering the low (less than $0.15 \mathrm{mg} \mathrm{m}^{-3}$ ) total Chl biomass levels.

In Fig. 7d PhytoANN exhibits a very different community composition pattern characteristic of the WCAtl. Here, cyanobacteria dominate from summer to winter, while coccolithophores temporarily dominate the community from March until May. Diatoms reach a peak in their relative contribution in March. These results, similar to NOBM, are consistent with observations at BATS, where haptophytes make up between 25 and $46 \%$ of total phytoplankton biomass (Lomas and Bates, 2004). At the BATS site, haptophytes are mostly composed of coccolithoporids such as Emiliania huxleyi (Haidar and Thierstein, 2001). PhytoANN and NOBM predict very little chlorophyte activity under these environmental conditions. However, according to Lomas and Bates (2004), pelagophytes and prasinophytes (but not dinoflagel- 
lates) can make up a substantial proportion of the winterspring bloom population, on average around $15 \%$. We note that PhytoANN and NOBM do not capture the observed significant interannual variability in the ratio of chlorophytes to cyanobacteria during the bloom season (Lomas and Bates, 2004).

Very low phyto-PFT biomass levels are also estimated for the CPac region (Fig. 7f). PhytoANN captures patterns simulated by NOBM very well, namely that cyanobacteria are most abundant year-round. Coccolithophores increase slightly in concentration during summer months. Diatoms and chlorophytes have extremely low biomass levels. Compared to the WCAtl box, they show no increase during the winter-spring bloom period.

We find large differences between PhytoANN and NOBM results in all HNLC regions. In the EEP, both models show a similar weak seasonal variability with only a slight increase in early fall (Fig. 7e). The peak can be attributed to a coincident maximum tropical instability wave activity that enhances upwelling of cold, nutrient-rich waters and thus promotes higher new production (e.g., Evans et al., 2009; Strutton et al., 2001; Vichi et al., 2008). PhytoANN predicts chlorophytes to dominate the phytoplankton community and diatoms and coccolithiphores to be much lower in biomass. This is in marked contrast to the climatology picture from NOBM, where diatoms are by far the most dominant functional group, indicating a very different interpretation of their role in the EEP ecosystem. According to the PHYSAT diagnostic and PISCES dynamic models (Gorgues et al., 2010) diatoms rarely dominate in this region. In fact, their contribution to total phytoplankton biomass does not exceed $10 \%$ on average. This long-term low diatom biomass level has also been confirmed by several field estimates conducted at distinct locations and at different times of the year (Blanchot et al., 2001; Dandonneau et al., 2004; Taylor et al., 2011). Average diatom biomass estimated by the bio-optical algorithm is even lower than in PhytoANN (Fig. 8b), and is thus closest to field observations. Our PhytoANN model predicts no marked differences in the seasonal distribution of coccolithophores, which are more abundant than diatoms on an annual average. This is consistent with bio-optical estimates of haptophytes (Fig. 8b). PIC climatology also indicates little seasonal variability and concentration levels much lower than in the NEAtl (Fig. 8b compared to Fig. 8a).

The NEPac region reveals the largest inconsistencies between models and observations in diatom and coccolithophore monthly climatologies. According to NOBM, diatoms reach highest absolute biomass in NEPac, higher even than in the North Atlantic. They reach their spring peak in May and their fall peak in September (Fig. 7g). Chlorophytes maintain low biomass but flourish in the fall. Maximum chlorophyte biomass level is approximately half that of diatoms during their peak in September. Coccolithophores and cyanobacteria do not appear affected by strong seasonality in the environmental forcing and contribute little, if at all, to total phytoplankton biomass. PhytoANN, on the other hand, predicts a very different phyto-PFT distribution in response to changing environmental conditions. Here, coccolithophores remain the dominant group throughout the year. Their biomass is highest in May but does not decline much until October. Diatoms peak in May but have drastically lower biomass levels from July to March. In contrast to NOBM, PhytoANN diatoms do not bloom in the fall. In PhytoANN, this late peak is attributed to coccolithophores and chlorophytes.

How does this correspond to what we know about climatology of these phyto-PFTs? Analyzing the seasonality of coccolithophore blooms in the Bering Sea, Iida et al. (2002) found significant interannual variability in the peak areal coverage between 1998 and 2001. The general pattern, however, suggested a spring peak between April and May and a fall peak between August and September. Up to two-month shifts were recorded for exceptionally warm years (1998) and cold years (1999) caused by anomalous El Niño-Southern Oscillation (ENSO) activity in the equatorial Pacific. According to the bio-optical model, haptophytes follow the diatom distribution closely. They exhibit a strong but smaller than diatom increase in biomass in May and a weaker but greater than diatom increase in biomass in November (Fig. 8c). This picture is thus most similar to NOBM. PIC estimates suggest that coccolithophores are very abundant from March to October and reach a maximum in September. It appears that both NOBM and the bio-optical algorithm attribute much of the summer and fall $\mathrm{Chl}$ to diatoms rather than coccolithophores, in contrast to in situ (Iida et al., 2002) and remote sensing observations (Fig. 8c). We know that the PhytoANN overestimates the proportion of coccolithophores on the annual basis (Fig. 6c), yet its monthly climatology is closer to the one revealed by PIC and in situ data compared to NOBM and the bio-optical model. It is puzzling, however, that PIC does not reveal a maximum spring coccolithophore peak seen in Iida et al. (2002) and simulated by all the models. Regardless of the discrepancies between timing and magnitude of diatom and coccolithophore blooms in the NEPac, it is clear that PhytoANN correctly predicts that coccolithophores are at least as dominant as diatoms in the region. Therefore, it provides an improvement over its training model, NOBM, which does not allow coccolithophores for to utilize a very favorable ecological niche. We consider this result the most important evaluation of our PhytoANN ecological indicator model.

In the AntAtl, NOBM predicts an absolute dominance of diatoms that reaches its maximum levels between November and January (Fig. 7h). There is a small chlorophyte increase following the winter diatom bloom, but no seasonal response of coccolithophores. This is in marked contrast to both the bio-optical model and PIC estimates. The bio-optical model shows that haptophytes follow the seasonal distribution of diatoms and that their biomass is higher than diatoms in all seasons except for November-January, when they are more 
or less equal. PIC climatology is similarly characterized by a winter maximum and a summer minimum. We also observe that the AntAtl PIC maximum is lower than the boreal summer and early fall maximum in NEPac, and at the same time higher than the boreal winter PIC minimum in NEPac. This observation is consistent with the monthly global climatology analysis of Moore et al. (2012), whose coccolithophore bloom classifier describes eight optical water types from multiple satellite sensors.

PhytoANN's monthly coccolithophore climatology matches well with bio-optical algorithm results, also in relation to other basins. Furthermore, PhytoANN suggests that chlorophytes constitute a substantial portion of total $\mathrm{Chl}$ from April to September (close to $50 \%$ ). This is in close agreement with another bio-optical model result of Alvain et al. (2008, their Fig. 10), who, based on 1998-2006 monthly climatology, predicted that diatoms contribute at most $52 \%$ to total $\mathrm{Chl}$ and that nanoflagellates (most equivalent to our chlorophytes) contribute over $80 \%$ from April to September in the Southern Ocean $\left(40-70^{\circ} \mathrm{S}, 180\right.$ $\left.180^{\circ} \mathrm{E}\right)$. We conclude that PhytoANN is able to improve the phyto-PFT monthly climatology picture from NOBM in the AntAtl using the knowledge of ecological rules inferred during training from the NOBM itself.

Quantifying coccolithophore biomass has been extremely difficult both in dynamic and diagnostic models. Except for the recently improved PhytoDOAS algorithm (Sadeghi et al., 2012), most bio-optical models show the spatial extent of bloom areas (Alvain et al., 2008; Moore et al., 2012). When analyzing the results of the Dynamic Green Ocean Model, Le Quéré et al. (2005) noted that model calcifiers grow between $40^{\circ} \mathrm{N}$ and $40^{\circ} \mathrm{S}$ but they are almost absent poleward of these latitudes. Satellite observations following the method of Brown and Yoder (1994) reveal highest coccolithophore bloom frequencies in the $40-70^{\circ}$ latitude band of both hemispheres (Le Quéré et al., 2005, their Fig. 10). Le Quéré et al. (2005) suggested that this is because the traits defined for calcifiers and the zooplankton that graze on them do not give calcifiers a competitive advantage at high latitudes. Compared to other PFTs, they have a lower maximum growth rate, higher light affinity and lower resistance to darkness. In the NOBM, coccolithophores are very abundant beyond $40^{\circ}$ of latitude but only in the North Atlantic. In high latitudes of other basins they are severely outcompeted by diatoms (Gregg and Casey, 2007). Current dynamic model results indicate that we have an insufficient knowledge of either traits of calcifiers (e.g., vital rates) or their protective defenses against zooplankton grazing (Strom, 2002). Even though our PhytoANN considers neither nutrient competition nor zooplankton grazing responses, it provides a more realistic and ecologically consistent picture of coccolithophore distribution in the high-latitude regions.
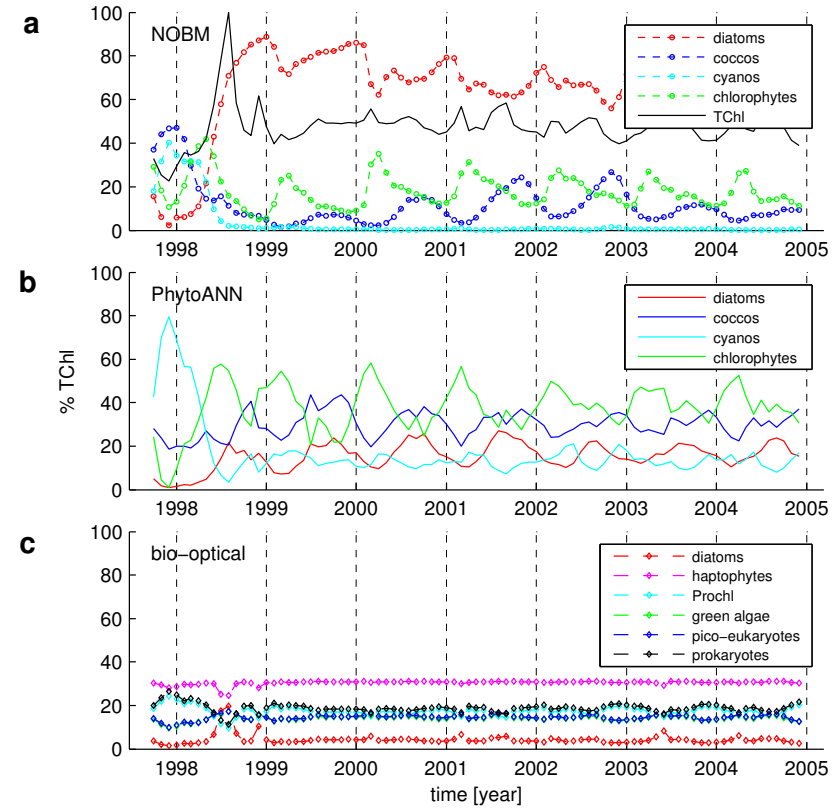

Fig. 9. October 1997-December 2004 time series of the percentage contribution to total Chl of four phyto-PFTs in the EEP from (a) NOBM and (b) PhytoANN, as well as that (c) of six phyto-PFTs from the bio-optical algorithm (Hirata et al., 2013). Additionally, time series of total Chl (normalized to units of percentage contribution) measured by SeaWiFS is included in panel (a). Variability in total $\mathrm{Chl}$ corresponds equally to total $\mathrm{Chl}$ in the PhytoANN (which normalizes total phyto-PFT biomass to total SeaWiFS Chl), the biooptical model Chl and the NOBM (which assimilates satellite Chl).

\subsection{Dramatic shifts in phyto-PFT distribution}

We also wanted to check how our diagnostic model performs when it comes to projecting changes under extreme input conditions. Here, we choose to focus on the EEP where ENSO contributes the most to temporal variability (Wang and Fiedler, 2006, and references therein). ENSO cycles not only shift total biomass by almost two orders of magnitude but also alter the phytoplankton community composition significantly. In order to really test the PhytoANN response to the extreme 1997-1999 El Niño and La Niña events, we did not only exclude the EEP but also the October 1997December 1999 period from all data used for confirmatory analysis.

In Fig. 9a we first note that the NOBM captures a sharp decrease in diatoms percentage contribution to total Chl during El Niño. The coincident decrease in chlorophytes contribution is not distinct from the monthly climatological pattern (Fig. 7e). Coccolithophores and cyanobacteria respond positively to the warmer but nutrient-poor El Niño conditions. In the PhytoANN, both diatoms and chlorophytes contribute much less to total Chl from October 1997 to summer 1998 than on a long-term average (Fig. 9b). Also, contrary to the NOBM, coccolithophores do not increase their contribution 
to total $\mathrm{Chl}$ in response to El Niño. In turn, cyanobacteria dominate the phytoplankton population as they constitute up to $80 \%$ of total Chl biomass around the peak of El Niño conditions.

In response to the subsequent increase in total Chl during La Niña event, diatoms in the NOBM restore their high contribution, achieving more than $80 \%$ of total Chl by fall 1998. In contrast, coccolithophores and cyanobacteria in the NOBM reach their minimum contribution to total Chl by the beginning of 1999. We also note that the 1997-2005 mean diatom percentage contribution is grossly overestimated in the NOBM. In the PhytoANN, we see a different response of the phytoplankton community. All phyto-PFTs return to their average contribution levels but do not reveal the expected equally dramatic changes in phytoplankton community composition associated with La Niña high Chl blooms. The substantial increase in Chl is mostly attributed to chlorophytes and only secondly to diatoms. Compared to the NOBM results, the PhytoANN suggests more coexistence of phytoPFTs even under the extreme La Niña conditions. We also note that along the entire time series we see evidence of coccolithophores becoming the dominant group at times (fall 1999 and 2000) in PhytoANN (Fig. 9b). NOBM simulates interannual variability in coccolithophore biomass as well but in different years (fall 2002 and 2003) and never beyond the diatom levels (Fig. 9a). This suggests that the two models also predict different ecological responses of phyto-PFTs to interannual changes in the ecology of the EEP.

In the bio-optical model (Fig. 9c), haptophytes, which include but are not limited to coccolithophores, dominate the biomass spectrum consistently throughout the entire time series. The sum of Prochlorococcus and prokaryotes are on a similar level to cyanobacteria modeled by the PhytoANN, but markedly higher than in the NOBM. Diatoms remain on a very low (less than $10 \%$ ) level of contribution to total Chl, in close agreement with in situ observations (e.g., Taylor et al., 2011). The bio-optical model reveals a moderate increase in Prochlorococcus and prokaryotes contribution to total Chl during El Niño, and it also captures the large increase in diatom contribution during the subsequent $\mathrm{La}$ Niña event. During this time diatoms far exceed their longterm average levels. Such a response was also indicated by in situ (Chavez et al., 1999), dynamic (Gorgues et al., 2010) and some remote sensing (Masotti et al., 2011) modeling studies, which report that diatoms first decreased and later increased significantly in response to El Niño and La Niña, respectively.

Based on these results, we can conclude that our diagnostic model appears to be moderately sensitive to extreme environmental perturbations and can detect only some significant temporal shifts in phytoplankton community composition. These shifts are suggested to occur even when total Chl levels do not fluctuate much. Neither the NOBM nor the PhytoANN fully capture the observed strong changes in diatom contribution during an extreme ENSO cycle. Both models perform better when simulating changes in response to El Niño rather than La Niña conditions. Higher spatial and temporal resolution of model estimates would allow for testing for whether our model is also sensitive to high-frequency submesoscale shifts in phyto-PFT distribution attributed to passing tropical instability waves (Palacz and Chai, 2012; Parker et al., 2011).

\subsection{Assessment of model limitations}

First, the ecological indicators used by PhytoANN do not include nutrients concentration and zooplankton grazing explicitly. Effects of changing nutrient concentrations are largely inferred from changes in SST, as SST and nitrate are often closely correlated, e.g., at the BATS site (Nelson et al., 2004). Including field measurements of $\mathrm{Si}$ and $\mathrm{Fe}$ as separate indicators should potentially improve our model predictive skill. However, using NOBM nutrient fields as inputs did not improve PhytoANN performance in either confirmatory or exploratory analysis in any significant manner.

We realize that HNLC regions are primarily $\mathrm{Fe}$ limited, while the northern hemispheric Atlantic is not. Therefore, we would expect physiological mechanisms of some phytoPFTs in the exploratory regions to be different from those in the training regions. There are two main possible explanations as to why PhytoANN results in HNLC regions are closer to the observed in comparison to the NOBM (which uses $\mathrm{Fe}$ as a state variable). On the one hand, the PhytoANN could implicitly take the role of Fe in HNLC waters into account by assuming that $\mathrm{Fe}$-limiting conditions coincide with some combination of other indicators considered. Knowing that $\mathrm{Chl}$ is a strong indicator in the PhytoANN, implicit effects of Fe could be expected. On the other hand, it is possible that the PhytoANN only weakly, if at all, accounts for Felimited conditions but nevertheless projects more reasonable HNLC phytoplankton composition compared to NOBM. In such case, our PhytoANN results do not suggest that Fe is not an important physiological regulator but rather indicate that $\mathrm{Fe}$ is not necessarily a key indicator of phytoplankton community composition, or that Fe may not be adequately represented in current models. Scarce Fe measurements and the lack of their time series still limit the accuracy of Fe parameterizations, which in turn lead to potential errors in global biogeochemical models.

We speculate that some grazing effects are only implicitly included in our model through considering total Chl as an indicator. However, this does not resolve phyto-PFTspecific grazing pressures. Consequently, PhytoANN's interpretation of ecological rules distinguishing between phytoPFTs is strongly biased towards bottom-up control processes. We are currently developing a prototype of a similar model that includes feedback from key zooplankton PFTs. It is to be implemented in the North Atlantic Basin, where basin-wide long-term coverage of Continuous Plankton Recorder data enables such an experiment (Raitsos et al., 2008). 
Second, the source of several ecological indicators is common to the NOBM and the PhytoANN. This means that PhytoANN's interpretation of some the relationships between phyto-PFTs and the environment is not necessarily independent of NOBM's. However, this does not hinder the verification of our hypotheses, especially considering the large differences in phyto-PFT distributions in regions used only for exploratory analysis.

Third, we assume that the NOBM phyto-PFT distribution used in training most closely represents the in situ conditions in the Atlantic Basin. This assumption is based on the fact that NOBM assimilates SeaWiFS Chl data to correct for total PFT biomass levels and that it was generally positively evaluated against observations in the North Atlantic (Gregg and Casey, 2007), among other regions. Although in situ data would provide the ideal input, currently available in situ phyto-PFT biomass data, with strong seasonal and geographical bias, are insufficient to represent most of biogeochemical conditions in the open ocean.

Fourth, PhytoANN shows only a surface picture of phytoPFT biogeography. This limitation will be difficult to overcome considering that all remote sensing indicators provide a surface view themselves; however there are approaches that try to account for vertical changes in bio-optical algorithms (e.g., Uitz et al., 2006; Brewin et al., 2010).

\section{Implications}

The results of this study highlight the benefits of using advance statistical techniques to unravel complex and highly nonlinear ecological interactions, with implications for biogeosciences and marine ecosystem management alike. We demonstrate that, through an artificial neural network, we can combine remote sensing and dynamic model results to generate new, ecologically consistent estimates of phyto-PFT distribution in a wide range of biogeographic conditions. If ecological rules can be extracted from weights assigned to connections within PhytoANN, then we can provide biogeochemically specific parameterizations of phyto-PFT growth functions, which are currently too rigid to capture the global variability in phytoplankton vital rates. This approach should help model the global distribution of silicifiers and calcifiers correctly so that we can reduce the uncertainty on how much atmospheric carbon is being fixed into biomass and how much is being exported into the deep ocean (Francois et al., 2002; Rost and Riebesell, 2004; Sarmiento et al., 2002). In turn, this will improve our future projections of global carbon fluxes and climate mitigation plans.

Unlike other diagnostic PFT models, PhytoANN can be used to make future projections under scenarios of climateinduced changes to key environmental indicators. This is because it takes inputs that are also modeled by most coupled NPZD models running in forecast mode. In this study, we verify the hypothesis that PhytoANN is able to interpret the complex and nonlinear interactions between phyto-PFTs and the environment, at least to the same extent as the original training model, yet in a fraction of time required to perform a dynamic simulation. We speculate that our PhytoANN could be used to interpret similar relationships in an ensemble of coupled models and later applied to future time series of indicators of change. This would provide a novel framework for constructing such ensemble model projections to examine the differences and similarities between them, and eventually lead to better constrained future projections of PFT states.

Furthermore, PhytoANN-type models can further be developed to look at phytoplankton size classes and their dependency on changing environmental conditions, such as temperature. Shifts in community size spectrum in response to rising temperatures are suggested by some studies (e.g., Hilligsøe et al., 2011), yet in others they are shown to depend primarily on total biomass and productivity (e.g., Maranón et al., 2012). Hence, ANNs could prove useful in examining these interactions in the context of variability among biogeochemical provinces rather than global average trends.

Similarly, this approach can be potentially expanded to include higher trophic levels, from zooplankton functional groups to fish species. Depending on data availability among other things, this could first be tested within a single ecosystem. If successful, such a model could provide an alternative framework to the newly proposed general ecosystem models (GEMs) that aim at resolving complex and adaptive properties of ecosystems (Purves et al., 2013). ANNs are already heavily relied upon in system control and management applications in other disciplines such as electrical engineering, medical science or business and economics (Anandarajan et al., 2001; Jaeger and Haas, 2004; Khan et al., 2001). Here, we demonstrate that only very few measurable, specific and sensitive indicators of change of phyto-PFTs are sufficient to capture key seasonal to interannual patterns of their distribution. While it is far more difficult to include indicators of change of key zooplankton and fish species in an ANN framework, such efforts are being currently undertaken under the auspices of the European Union 7th Framework EURO-BASIN (European Basin-scale Analysis, Synthesis and Integration) project (http://www.euro-basin.eu/). 


\section{Appendix A}

\section{PhytoANN training and evaluation}

Table A1. Spatial and temporal characteristics of the input and target data used in confirmatory and exploratory analysis.

\begin{tabular}{lll}
\hline & confirmatory analysis & exploratory analysis \\
\hline spatial resolution & $1^{\circ}$ & box average \\
temporal resolution & monthly & monthly \\
time series length & Jan 2000-Dec 2004 & Oct 1997-Dec 2004 \\
\hline
\end{tabular}

Table A2. Range of input values (min-max) of all ecological indicators used during training and exploration.

\begin{tabular}{cccccc}
\hline & $\begin{array}{c}\mathrm{SST} \\
{\left[{ }^{\circ} \mathrm{C}\right]}\end{array}$ & $\begin{array}{c}\mathrm{PAR} \\
{\left[\mathrm{W} \mathrm{m}^{-2}\right]}\end{array}$ & $\begin{array}{c}\text { MLD } \\
{[\mathrm{m}]}\end{array}$ & $\begin{array}{c}\text { Wspd } \\
{\left[\mathrm{m} \mathrm{s}^{-1}\right]}\end{array}$ & $\begin{array}{c}\mathrm{Chl} \\
{\left[\mathrm{mg} \mathrm{m}^{-3}\right]}\end{array}$ \\
\hline $\begin{array}{c}\text { training } \\
\text { exploration }\end{array}$ & $2.01-29.9$ & $2.03-60.6$ & $2.72-16.4$ & $10.9-400$ & $0.03-5.25$ \\
& $3.12-29.0$ & $6.97-55.4$ & $4.18-12.5$ & $14.2-192$ & $0.06-1.20$
\end{tabular}

In order to avoid overfitting and to assure the generality of our model, we use the early stopping procedure. In this technique, the available data are divided into three subsets: training, validation and testing. The training set $(70 \%$ of confirmatory analysis data) is used for computing the gradient and updating the network weights and biases. The validation set ( $15 \%$ of confirmatory analysis data) is used to monitor the error during the training process because it initially decreases but later typically increases as the network begins to overfit the data. Hence, when the validation error increases for a specified number of iterations (six in this study), the training is stopped, and the weights and biases at the minimum of the validation error are returned. The error calculated from the testing set ( $15 \%$ of confirmatory analysis data) is not used during training explicitly. However, it is plotted during the training process to monitor whether the error in the testing set reaches a minimum at a significantly different iteration number than the validation set error. In such cases, it would indicate a poor division of the data set and a need for re-training.

It is not required to select only linearly independent indicators as inputs to the ANN because it performs dimensionality reduction on its own. Similarly, we do not remove any outliers because we assume the ANN is capable of distinguishing between signal and noise after analyzing a sufficient number of training examples. We do, however, need to normalize the input data onto a common min-max scale to prevent indicators with highest absolute values from overpowering the neurons. Moreover, if the indicators or targets have a non-normal distribution, then the ANN will produce results biased towards the more populated end of their range. In this study, we thus log-normalize MLD and Chl in the input layer and all four phyto-PFTs in the output layer. All
Table A3. Default PhytoANN parameters chosen for this study.

\begin{tabular}{ll}
\hline Parameter & Value \\
\hline ANN type & Feedforward \\
\#hidden layers & 1 \\
\#neurons in hidden layer & 8 \\
\#inputs & 5 \\
\#outputs & 4 \\
1st layer transfer function & tangential sigmoidal \\
2nd layer transfer function & linear \\
Learning rate parameter & dynamic \\
Training algorithm & Levenberg-Marquardt \\
Data division mode & random, every sample \\
training: validation : testing [\%] & $70: 15: 15$ \\
Generalization scheme & early stopping \\
Performance function & mean-squared error \\
\hline
\end{tabular}

values are then back-transformed to linear scales only after training and simulation are completed.

We also note that climatology and time series results presented in this study are in fact ensemble mean results from 10 PhytoANNs. No two ANNs are exactly the same because they are trained using random weight and bias vector initialization as well as a random distribution of data point indices assigned to training, evaluation or testing. Though individual simulations reveal variable absolute values of phyto-PFT biomass, their time series distribution patterns are very robust. Therefore, we consider ensemble means as optimal representations of PhytoANN results.

In Table A3 we provide the details of the PhytoANN architecture common to all ensemble members, chosen as optimal for this study. Results in Table A4 show how increasing the number of neurons in the hidden layer (ANN complexity) increases the fit to the entire confirmatory data (both log-transformed and linear). In theory, the optimum number of neurons depends on the degree of linear independence of the patterns in hidden layer space (Teoh et al., 2006). We note that a good fit is obtained even when using the simplest architecture. However, an inspection of time series distributions reveals that not all expected patterns are well captured by a five-neuron ANN. On the other hand, the 10- and 15neuron nets are likely overfitted to the training data because they do not increase the fit substantially (Table A4). We concluded that the eight-neuron ANN was well fitted yet general enough to simulate phyto-PFTs, also in a relatively short time (average of $228 \mathrm{~s}$ per training).

In Table A5 we provide more detailed information about the performance of the algorithm when applied to all points from within the training regions. The fit between PhytoANN and NOBM biomass is very good in most cases (above $70 \%$ ), but visibly lower for cyanobacteria and for all phyto-PFTs in the WCAtl. Differences between correlation coefficient $(R$ coeff) performance in training, testing and evaluation subsets are negligible, on the order of 0.01 , which confirms a good 
Table A4. Results of the sensitivity analysis on PhytoANN's number of neurons in the hidden layer. Metrics are number of training iterations (epochs), training time, correlation coefficient and normalized mean-squared error on log-transformed and normal data. Presented statistics are ensemble means from five runs under the same configuration but different sample division and weight and bias initialization. Values in parentheses represent statistics for diatoms, coccolithophores, cyanobacteria and chlorophytes, respectively.

\begin{tabular}{lllllll}
\hline \#N & epochs & time $[\mathrm{s}]$ & $R_{\log 10}$ & $R_{\operatorname{lin}}$ & $\mathrm{NMSE}_{\log 10}[\%]$ & $\mathrm{NMSE}_{\operatorname{lin}}[\%]$ \\
\hline 5 & 144 & 182 & $0.88(0.82-0.84-0.84-0.93)$ & $0.51(0.45-0.64-0.65-0.52)$ & $28(50-41-40-15)$ & $96(96-96-99-210)$ \\
$\mathbf{8}$ & $\mathbf{1 2 5}$ & $\mathbf{2 2 7}$ & $\mathbf{0 . 8 9}(\mathbf{0 . 8 3 - 0 . 8 8 - 0 . 8 5 - 0 . 9 4 )}$ & $\mathbf{0 . 5 4}(\mathbf{0 . 6 1 - 0 . 8 3 - 0 . 5 4 - 0 . 4 5})$ & $\mathbf{2 6}(\mathbf{4 6 - 2 9 - 3 8 - 1 3})$ & $\mathbf{8 1}(\mathbf{8 4 - 5 8 - 7 4 - 1 1 0})$ \\
10 & 150 & 312 & $0.90(0.83-0.89-0.86-0.94)$ & $0.79(0.61-0.87-0.57-0.73)$ & $25(45-25-36-13)$ & $47(110-34-72-76)$ \\
15 & 179 & 489 & $0.90(0.84-0.90-0.87-0.95)$ & $0.81(0.68-0.88-0.62-0.66)$ & $23(41-24-33-12)$ & $45(78-31-65-82)$ \\
\hline
\end{tabular}

Table A5. PhytoANN's performance with respect to the NOBM for regions and times used for training. Goodness of fit is represented by the correlation coefficient ( $R$-coeff) on log-transformed phyto-PFT biomass values. Results are ensemble means and 1 standard deviation from all 10 ANNs.

\begin{tabular}{lllll}
\hline & NEAtl & NorwSea & WCAtl & EqAtl \\
\hline diatoms & $0.68 \pm 0.02$ & $0.72 \pm 0.08$ & $0.65 \pm 0.01$ & $0.76 \pm 0.03$ \\
coccolithophores & $0.63 \pm 0.04$ & $0.70 \pm 0.07$ & $0.45 \pm 0.04$ & $0.78 \pm 0.07$ \\
cyanobacteria & $0.73 \pm 0.03$ & $0.28 \pm 0.04$ & $0.56 \pm 0.04$ & $0.47 \pm 0.08$ \\
chlorophytes & $0.72 \pm 0.02$ & $0.83 \pm 0.03$ & $0.42 \pm 0.08$ & $0.87 \pm 0.01$ \\
\hline
\end{tabular}

Table A6. Results of the sensitivity analysis on PhytoANN's type of training algorithm. Metrics are correlation coefficient and normalized mean-squared error on log-transformed data, number of training iterations (epochs) and training time. Presented statistics are ensemble means from five runs under same configuration but different sample division and weight and bias initialization. Values in parentheses represent statistics for diatoms, coccolithophores, cyanobacteria and chlorophytes, respectively.

\begin{tabular}{lllll}
\hline Training algorithm & Training fit $(R$-coeff $)$ & NMSE $[\%]$ & epochs & time $[\mathrm{s}]$ \\
\hline Levenberg-Marquardt & $\mathbf{0 . 8 9}(\mathbf{0 . 8 3 - 0 . 8 8 - 0 . 8 5 - 0 . 9 4 )}$ & $\mathbf{2 6}(\mathbf{4 6 - 2 9 - 3 8 - 1 3})$ & $\mathbf{1 2 5}$ & $\mathbf{2 2 7}$ \\
Variable learning rate & $0.75(0.47-0.44-0.81-0.44)$ & $76(290-209-54-454)$ & 98 & 21 \\
Bayesian regularization & $0.89(0.83-0.89-0.85-0.94)$ & $25(46-25-38-13)$ & 362 & 644 \\
BFGS quasi-Newton & $0.89(0.83-0.87-0.85-0.93)$ & $27(46-31-40-15)$ & 218 & 90 \\
\hline
\end{tabular}

partitioning of available data between the three subsets. It is important to note that the algorithm training procedure is in fact optimized on the basis of an aggregate training data set (all PFTs from all four regions), which explains the difference in performance measures listed in Table A5 and Table A6.
Table A6 also reveals that the Levenberg-Marquardt and the BFGS quasi-Newton training algorithms provide equally good fits to the data and take little time to perform. Except for the fact that the Levenberg-Marquardt algorithm is more common in feedforward-type ANNs, its choice here is arbitrary. We relied on vast literature accounts of the usage of transfer and performance functions and did not test the sensitivity to the choice of these functions here. 


\section{Appendix B}

\section{Ecological niches of phyto-PFTs in NOBM}
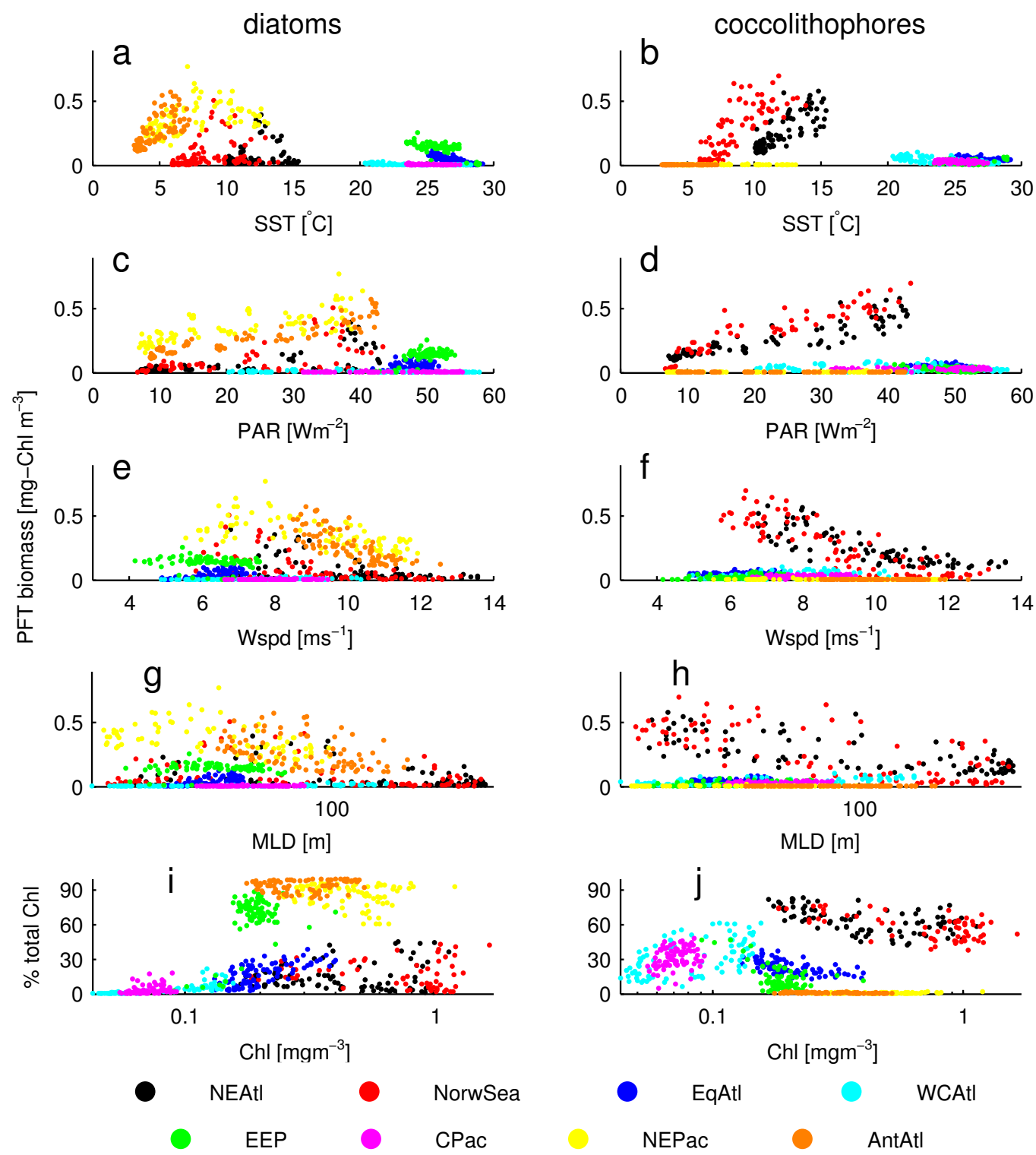

Fig. B1. Scatter plots showing the emerging relationship between NOBM diatom (left column) and coccolithophore (right column) biomass $\left[\mathrm{mgChl} \mathrm{m}^{-3}\right](\mathbf{a}-\mathbf{h})$ or \% of total Chl (i, j) vs. individual ecological indicators color coded according to domain of origin. On the $x$ axis from top to bottom: SST, PAR, Wspd, MLD and Chl. All data points come from exploratory analysis only, and thus they are box average and monthly average estimates from October 1997 to December 2004. 

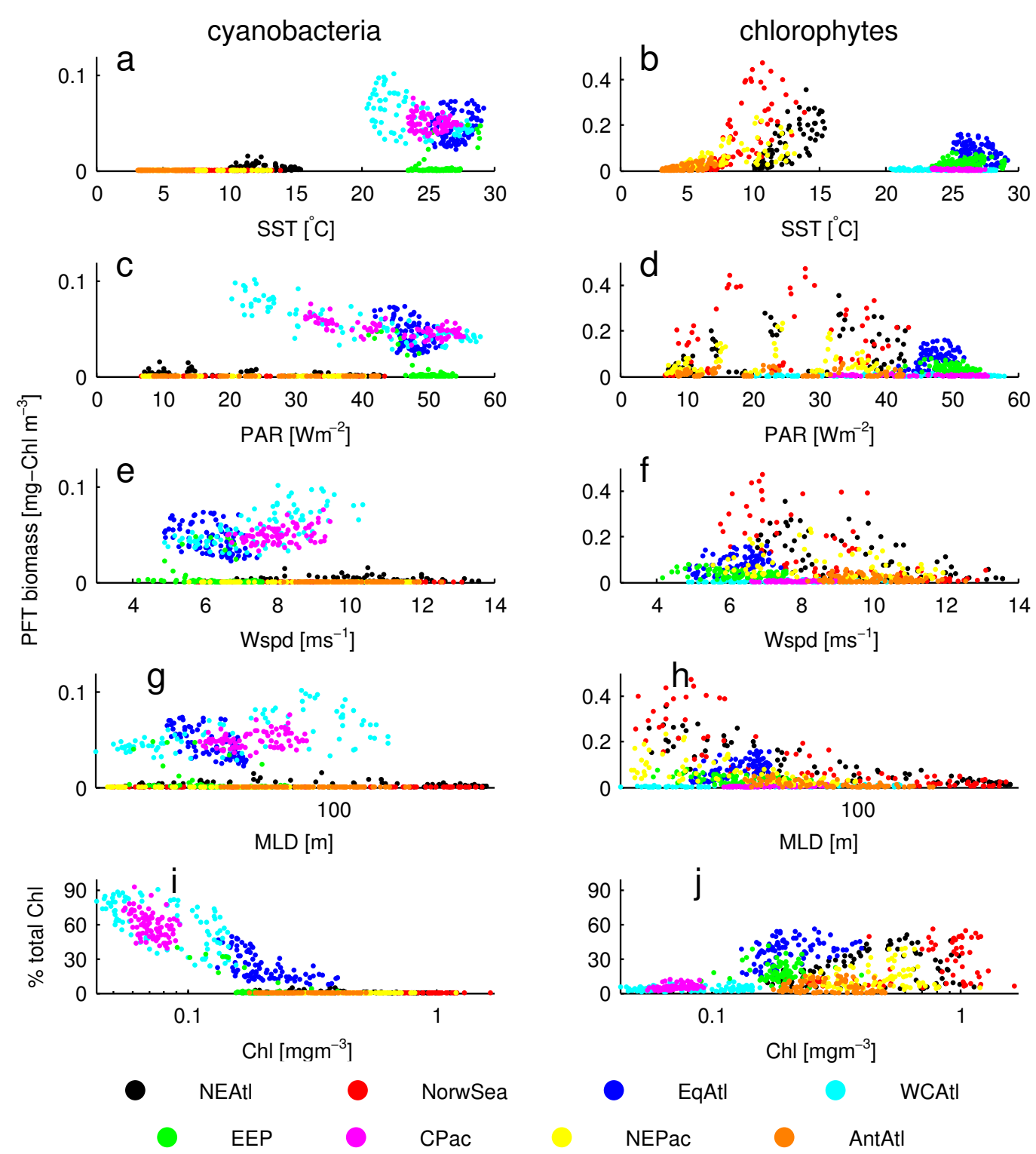

Fig. B2. Scatter plots showing the emerging relationship between NOBM cyanobacteria (left column) and chlorophyte (right column) biomass $\left[\mathrm{mgChlm}^{-3}\right](\mathbf{a}-\mathbf{h})$ or $\%$ of total Chl $(\mathbf{i}, \mathbf{j})$ vs. individual ecological indicators color coded according to domain of origin. On the $x$ axis from top to bottom: SST, PAR, Wspd, MLD and Chl. All data points come from exploratory analysis only, and thus they are box average and monthly average estimates from October 1997 to December 2004. 
Acknowledgements. The authors would like to thank the many collaborators from the EURO-BASIN project for valuable suggestions and criticism at the early stages of this work. We also thank Patrizio Mariani, Thomas Kiorbøe, Ken Andersen, Fi Prowe and Ivo Grigorov from DTU-Aqua for comments and suggestions. The research was (co-)funded by European Union Seventh Framework Programme project EURO-BASIN, European Basin-scale Analysis, Synthesis and Integration in the North Atlantic (grant agreement no. 264933).

Edited by: M. Grégoire

\section{References}

Alkire, M. B., D’Asaro, E., Lee, C., Jane Perry, M., Gray, A., Cetinić, I., Briggs, N., Rehm, E., Kallin, E., Kaiser, J., and Gonzalez-Posada, A.: Estimates of net community production and export using high-resolution, Lagrangian measurements of $\mathrm{O}_{2}, \mathrm{NO}_{3}^{-}$, and POC through the evolution of a spring diatom bloom in the North Atlantic, Deep-Sea Res. Pt. I, 64, 157, doi:10.1016/j.dsr.2012.01.012, 2012.

Alvain, S., Moulin, C., Dandonneau, Y., and Loisel, H.: Seasonal distribution and succession of dominant phytoplankton groups in the global ocean: a satellite view, Global Biogeochem. Cy., 22, 1-15, doi:10.1029/2007GB003154, 2008.

Anandarajan, M., Lee, P., and Anandarajan, A.: Bankruptcy prediction of financially stressed firms: an examination of the predictive accuracy of artificial neural networks, Intelligent Systems in Accounting, Finance and Management, 10, 69-81, doi:10.1002/isaf.199, 2001.

Anderson, T. R.: Plankton functional type modelling: running before we can walk?, J. Plankton Res., 27, 1073-1081, doi:10.1093/plankt/fbi076, 2005.

Balch, W., Drapeau, D., Bowler, B., Lyczkowski, E., Booth, E., and Alley, D.: The contribution of coccolithophores to the optical and inorganic carbon budgets during the Southern Ocean Gas Exchange Experiment: new evidence in support of the Great Calcite Belt hypothesis, J. Geophys. Res., 116, C00F06, doi:10.1029/2011JC006941, 2011.

Balch, W. M.: Re-evaluation of the physiological ecology of coccolithophores, in: Coccolithophores. From Molecular Processes to Global Impact, edited by: Thierstein, H. R. and Young, J. R., Springer, Berlin, 165-190, 2004.

Balch, W. M.: Calcium carbonate measurements in the surface global ocean based on Moderate-Resolution Imaging Spectroradiometer data, J. Geophys. Res., 110, C07001, doi:10.1029/2004JC002560, 2005

Barton, A. D., Dutkiewicz, S., Flierl, G., Bragg, J., and Follows, M. J.: Patterns of diversity in marine phytoplankton, Science, 327, 1509-1511, doi:10.1126/science.1184961, 2010.

Barton, A., Finkel, Z., Ward, B., Johns, D., and Follows, M.: On the roles of cell size and trophic strategy in North Atlantic diatom and dinoflagellate communities, Limnol. Oceanogr, 58, 254-266, doi:10.4319/lo.2013.58.1.0254, 2013.

Beaugrand, G., McQuatters-Gollop, A., Edwards, M., and Goberville, E.: Long-term responses of North Atlantic calcifying plankton to climate change, Nat. Clim. Change, 3, 263-267, doi:10.1038/NCLIMATE1753, 2012.
Blanchot, J., André, J.-M., Navarette, C., Neveux, J., and Radenac, M.-H.: Picophytoplankton in the equatorial Pacific: vertical distributions in the warm pool and in the high nutrient low chlorophyll conditions, Deep-Sea Res. Pt. I, 48, 297-314, doi:10.1016/S0967-0637(00)00063-7, 2001.

Blanchard, J. L., Coll, M., Trenkel, V. M., Vergnon, R., Yemane, D., Jouffre, D., Link, J. S., and Shin, Y.-J.: Trend analysis of indicators: a comparison of recent changes in the status of marine ecosystems around the world, ICES J. Mar. Sci., 67, 732-744, doi:10.1093/icesjms/fsp282, 2010.

Bopp, L., Aumont, O., Cadule, P., Alvain, S., and Gehlen, M. Response of diatoms distribution to global warming and potential implications: a global model study, Geophys. Res. Lett., 32, L19606, doi:10.1029/2005GL023653, 2005.

Boyd, P. W. and Doney, S. C.: Modelling regional responses by marine pelagic ecosystems to global climate change, Geophys. Res. Lett., 29, 1-4, doi:10.1029/2001GL014130, 2002.

Bracher, A., Vountas, M., Dinter, T., Burrows, J. P., Röttgers, R., and Peeken, I.: Quantitative observation of cyanobacteria and diatoms from space using PhytoDOAS on SCIAMACHY data, Biogeosciences, 6, 751-764, doi:10.5194/bg-6-751-2009, 2009.

Brewin, R. J. W., Sathyendranath, S., Hirata, T., Lavender, S. J., Barciela, R. M., and Hardman-Mountford, N. J.: A three-component model of phytoplankton size class for the Atlantic Ocean, Ecol. Model., 221, 1472-1483, doi:10.1016/j.ecolmodel.2010.02.014, 2010.

Brewin, R. J. W., Hardman-Mountford, N. J., Lavender, S. J., Raitsos, D. E., Hirata, T., Uitz, J., Devred, E., Bricaud, A., Ciotti, A., and Gentili, B.: An intercomparison of bio-optical techniques for detecting dominant phytoplankton size class from satellite remote sensing, Remote Sens. Environ., 115, 325-339, doi:10.1016/j.rse.2010.09.004, 2011.

Brown, C. and Yoder, J.: Coccolithophorid blooms in the global ocean, J. Geophys. Res., 99, 7467-7482, doi:10.1029/93JC02156, 1994.

Carton, J. and Giese, B.: A reanalysis of ocean climate using Simple Ocean Data Assimilation (SODA), Mon. Weather Rev., 136, 2999-3017, doi:10.1175/2007MWR1978.1, 2008.

Cetinić, I., Perry, M., Briggs, N., Kallin, E., D’Asaro, E., and Lee, C.: Particulate organic carbon and inherent optical properties during 2008 North Atlantic Bloom Experiment, J. Geophys. Res., 117, C06028, doi:10.1029/2011JC007771, 2012.

Chavez, F., Strutton, P., Friederich, G., Feely, R., Feldman, G., Foley, D., and McPhaden, M.: Response of the equatorial Pacific Ocean to the 1997-1998 El Nino, Science, 286, 2126-2131, 1999.

Claustre, H., Bishop, J., Boss, E., Bernard, S., Berthon, J.-F., Coatanoan, C., Johnson, K., Lotiker, A., Ulloa, O., Perry, M. J., D'Ortenzio, F., Fanton D'andon, O. H., and Uitz, J.: Biooptical profiling floats as new observational tools for biogeochemical and ecosystem studies: potential synergies with ocean color remote sensing, in: Proceedings of OceanObs'09: Sustained Ocean Observations and Information for Society, vol. 2, edited by: Hall, J., Harrison, D. E., and Stammer, D., European Space Agency, Rome, ESA Publ. WPP-306, Venice, Italy, doi:10.5270/OceanObs09.cwp.17, 7 pp., 2010.

Commission, E.: Directive 2008/56/EC of the European Parliament and of the Council establishing a framework for community action in the field of marine environmental policy (Marine Strategy 
Framework Directive), Official Journal of the European Union, L164, 19-40, 2008.

Dale, V. H. and Beyeler, S. C.: Challenges in the development and use of ecological indicators, Ecol. Indic., 1, 3-10, doi:10.1016/S1470-160X(01)00003-6, 2001.

Dandonneau, Y., Deschamps, P.-Y., Nicolas, J.-M., Loisel, H., Blanchot, J., Montel, Y., Thieuleux, F., and Bécu, G.: Seasonal and interannual variability of ocean color and composition of phytoplankton communities in the North Atlantic, equatorial Pacific and South Pacific, Deep-Sea Res. Pt. II, 51, 303-318, doi:10.1016/j.dsr2.2003.07.018, 2004.

Devred, E., Sathyendranath, S., and Platt, T.: Delineation of ecological provinces using ocean colour radiometry, Mar. Ecol.-Prog. Ser., 346, 1-13, doi:10.3354/meps07149, 2007.

Edwards, M. and Richardson, A. J.: Impact of climate change on marine pelagic phenology and trophic mismatch, Nature, 430, 881-884, doi:10.1038/nature02808, 2004.

Evans, W., Strutton, P. G., and Chavez, F. P.: Impact of tropical instability waves on nutrient and chlorophyll distributions in the equatorial Pacific, Deep-Sea Res. Pt. I, 56, 178-188, 2009.

Fernandez, E., Boyd, P., Holligan, P., and Harbour, D.: Production of organic and inorganic carbon within a large-scale coccolithophore bloom in the northeast Atlantic Ocean, Mar. Ecol.Prog. Ser., 97, 271-285, 1993.

Follows, M. J., Dutkiewicz, S., Grant, S., and Chisholm, S. W.: Emergent biogeography of microbial communities in a model ocean, Science, 315, 1843-1846, doi:10.1126/science.1138544, 2007.

Francois, R., Honjo, S., Krishfield, R., and Manganini, S.: Factors controlling the flux of organic carbon to the bathypelagic zone of the ocean, Global Biogeochem. Cy., 16, 1087, doi:10.1029/2001GB001722, 2002.

Gorgues, T., Menkes, C., Slemons, L., Aumont, O., Dandonneau, Y., Radenac, M. H., Alvain, S., and Moulin, C.: Revisiting the La Niña 1998 phytoplankton blooms in the equatorial Pacific, Deep-Sea Res. Pt. I, 57, 567-576, 2010.

Gregg, W.: A coupled ocean general circulation, biogeochemical, and radiative model of the global oceans: seasonal distributions of ocean chlorophyll and nutrients, NASA Technical Memorandum 2000-209965, 33 pp., 2000.

Gregg, W. W.: Tracking the SeaWiFS record with a coupled physi$\mathrm{cal} / \mathrm{biogeochemical} /$ radiative model of the global oceans, DeepSea Res. Pt. II, 49, 81-105, doi:10.1016/S0967-0645(01)000959, 2002.

Gregg, W. and Casey, N.: Modeling coccolithophores in the global oceans, Deep-Sea Res. Pt. II, 54, 447-477, doi:10.1016/j.dsr2.2006.12.007, 2007.

Gregg, W. W., Ginoux, P., Schopf, P. S., and Casey, N. W.: Phytoplankton and iron: validation of a global three-dimensional ocean biogeochemical model, Deep-Sea Res. Pt. II, 50, 3143-3169, doi:10.1016/j.dsr2.2003.07.013, 2003.

Haidar, A. T. and Thierstein, H. R.: Coccolithophore dynamics off Bermuda (N. Atlantic), Deep-Sea Res. Pt. II, 48, 1925-1956, doi:10.1016/S0967-0645(00)00169-7, 2001.

Hashioka, T., Vogt, M., Yamanaka, Y., Le Quéré, C., Buitenhuis, E. T., Aita, M. N., Alvain, S., Bopp, L., Hirata, T., Lima, I., Sailley, S., and Doney, S. C.: Phytoplankton competition during the spring bloom in four Plankton Functional Type Mod- els, Biogeosciences Discuss., 9, 18083-18129, doi:10.5194/bgd9-18083-2012, 2012.

Hilligsøe, K. M., Richardson, K., Bendtsen, J., Sørensen, L.-L., Nielsen, T. G., and Lyngsgaard, M. M.: Linking phytoplankton community size composition with temperature, plankton food web structure and sea-air $\mathrm{CO}_{2}$ flux, Deep-Sea Res. Pt. I, 58, 826-838, doi:10.1016/j.dsr.2011.06.004, 2011.

Hirata, T., Aiken, J., Hardman-Mountford, N., Smyth, T., and Barlow, R.: An absorption model to determine phytoplankton size classes from satellite ocean colour, Remote Sens. Environ., 112, 3153-3159, doi:10.1016/j.rse.2008.03.011, 2008.

Hirata, T., Hardman-Mountford, N. J., Brewin, R. J. W., Aiken, J., Barlow, R., Suzuki, K., Isada, T., Howell, E., Hashioka, T., Noguchi-Aita, M., and Yamanaka, Y.: Synoptic relationships between surface Chlorophyll- $a$ and diagnostic pigments specific to phytoplankton functional types, Biogeosciences, 8, 311-327, doi:10.5194/bg-8-311-2011, 2011.

Hirata, T., Hardman-Mountford, N., and Brewin, R. J. W.: Comparing satellite-based phytoplankton classification methods, Eos Trans. AGU, 93, 59-60, doi:10.1029/2012EO060008, 2012.

Hirata, T., Saux-Picart, S., Hashioka, T., Aita-Noguchi, M., Sumata, H., Shigemitsu, M., Allen, J. I., and Yamanaka, Y.: A comparison between phytoplankton community structures derived from a global 3D ecosystem model and satellite observation, J. Marine Syst., 109-110, 129-137, doi:10.1016/j.jmarsys.2012.01.009, 2013.

Holland, J. H.: Hidden Order: How Adaptation Builds Complexity, Helix Books, Addison-Wesley Publishing Company, 1995.

Hutchinson, G. E.: The Paradox of the Plankton, Am. Nat., 95, 137$145,1961$.

Iida, T., Saitoh, S., Miyamura, T., Toratani, M., Fukushima, H., and Shiga, N.: Temporal and spatial variability of coccolithophore blooms in the eastern Bering Sea, 1998-2001, Prog. Oceanogr., 55, 165-175, doi:10.1016/S0079-6611(02)00076-9, 2002.

Jaeger, H. and Haas, H.: Harnessing nonlinearity: predicting chaotic systems and saving energy in wireless communication, Science, 304, 78-80, doi:10.1126/science.1091277, 2004.

Kara, A., Rochford, P., and Hurlburt, H.: Mixed layer depth variability over the global ocean, J. Geophys. Res., 108, 3079, doi:10.1029/2000JC000736, 2003.

Khan, J., Wei, J. S., Ringnér, M., Saal, L. H., Ladanyi, M., Westermann, F., Berthold, F., Schwab, M., Antonescu, C. R., Peterson, C., and Meltzer, P. S.: Classification and diagnostic prediction of cancers using gene expression profiling and artificial neural networks, Nat. Med., 7, 673-679, doi:10.1038/89044, 2001.

Lachkar, Z. and Gruber, N.: A comparative study of biological production in eastern boundary upwelling systems using an artificial neural network, Biogeosciences, 9, 293-308, doi:10.5194/bg-9293-2012, 2012.

Leblanc, K., Arístegui, J., Armand, L., Assmy, P., Beker, B., Bode, A., Breton, E., Cornet, V., Gibson, J., Gosselin, M.-P., Kopczynska, E., Marshall, H., Peloquin, J., Piontkovski, S., Poulton, A. J., Quéguiner, B., Schiebel, R., Shipe, R., Stefels, J., van Leeuwe, M. A., Varela, M., Widdicombe, C., and Yallop, M.: A global diatom database - abundance, biovolume and biomass in the world ocean, Earth Syst. Sci. Data, 4, 149-165, doi:10.5194/essd-4-149-2012, 2012. 
Lek, S. and Guegan, J.-F.: Artificial neural networks as a tool in ecological modelling, an introduction, Ecol. Model., 120, 65-73, 1999.

Le Quéré, C., Harrison, S., Colin Prentice, I., Buitenhuis, E., Aumont, O., Bopp, L., Claustre, H., Cotrim Da Cunha, L., Geider, R., Giraud, X., Klaas, C., Kohfeld, K. E., Legendre, L., Manizza, M., Platt, T., Rivkin, R. B., Sathyendranath, S., Uitz, J., Watson, A. J., and Wolf-Gladrow, D.: Ecosystem dynamics based on plankton functional types for global ocean biogeochemistry models, Glob. Change Biol., 11, 2016-2040, 2005.

Leterme, S. C., Edwards, M., Seuront, L., Attrill, M. J., Reid, P. C., and John, A. W. G.: Decadal basin-scale changes in diatoms, dinoflagellates, and phytoplankton color across the North Atlantic, Limnol. Oceanogr., 50, 1244-1253, doi:10.4319/lo.2005.50.4.1244, 2005.

Levin, S. A.: Ecosystems and the biosphere as complex adaptive systems, Ecosystems, 1, 431-436, 1998.

Link, J. S., Yemane, D., Shannon, L. J., Coll, M., Shin, Y.J., Hill, L., and Borges, M. D. F.: Relating marine ecosystem indicators to fishing and environmental drivers: an elucidation of contrasting responses, ICES J. Mar. Sci., 67, 787-795, doi:10.1093/icesjms/fsp258, 2010.

Lomas, M. and Bates, N.: Potential controls on interannual partitioning of organic carbon during the winter/spring phytoplankton bloom at the Bermuda Atlantic time-series study (BATS) site, Deep-Sea Res. Pt. I, 51, 1619-1636, doi:10.1016/j.dsr.2004.06.007, 2004.

Mahadevan, A., D’Asaro, E., Lee, C., and Perry, M. J.: Eddydriven stratification initiates North Atlantic spring phytoplankton blooms, Science, 337, 54-58, doi:10.1126/science.1218740, 2012.

Maranón, E., Cermeno, P., Latasa, M., and Tadonléké, R.: Temperature, resources, and phytoplankton size structure in the ocean, Limnol. Oceanogr., 57, 1266-1278, doi:10.4319/lo.2012.57.5.1266, 2012.

Margalef, R.: Life-forms of phytoplankton as survival alternatives in an unstable environment, Oceanol. Acta, 1, 493-509, 1978.

Masotti, I., Moulin, C., Alvain, S., Bopp, L., Tagliabue, A., and Antoine, D.: Large-scale shifts in phytoplankton groups in the Equatorial Pacific during ENSO cycles, Biogeosciences, 8, 539-550, doi:10.5194/bg-8-539-2011, 2011.

Minas, H. J. and Minas, M.: Net community production in high nutrient-low chlorophyll waters of the tropical and antarctic oceans - grazing vs. iron hypothesis, Oceanol. Acta, 15, 145$162,1992$.

Moore, T. S., Dowell, M. D., and Franz, B. A.: Detection of coccolithophore blooms in ocean color satellite imagery: a generalized approach for use with multiple sensors, Remote Sens. Environ., 117, 249-263, doi:10.1016/j.rse.2011.10.001, 2012.

Nelson, N., Siegel, D., and Yoder, J.: The spring bloom in the northwestern Sargasso Sea: spatial extent and relationship with winter mixing, Deep-Sea Res. Pt. II, 51, 987-1000, doi:10.1016/j.dsr2.2004.02.001, 2004.

O'Brien, C. J., Peloquin, J. A., Vogt, M., Heinle, M., Gruber, N., Ajani, P., Andruleit, H., Arístegui, J., Beaufort, L., Estrada, M., Karentz, D., Kopczyńska, E., Lee, R., Pritchard, T., and Widdicombe, C.: Global marine plankton functional type biomass distributions: coccolithophores, Earth Syst. Sci. Data Discuss., 5, 491-520, doi:10.5194/essdd-5-491-2012, 2012.
Palacz, A. P.: Advancing Ocean Management in the North Atlantic with Integrated Ecosystem Assessments and Artificial Neural Networks: What is the Potential of Using Coupled NPZD model and Satellite-Derived GES Time Series?, Technical University of Denmark (unpublished), 2012.

Palacz, A. P. and Chai, F.: Spatial and temporal variability in nutrients and carbon uptake during 2004 and 2005 in the eastern equatorial Pacific Ocean, Biogeosciences, 9, 4369-4383, doi:10.5194/bg-9-4369-2012, 2012.

Parker, A. E., Wilkerson, F. P., Dugdale, R. C., Marchi, A. M., Hogue, V. E., Landry, M. R., and Taylor, A. G.: Spatial patterns of nitrogen uptake and phytoplankton in the equatorial upwelling zone $\left(110^{\circ} \mathrm{W}-140^{\circ} \mathrm{W}\right)$ during 2004 and 2005, Deep-Sea Res. Pt. II, 58, 417-433, doi:10.1016/j.dsr2.2010.08.013, 2011.

Prowe, A. F., Pahlow, M., Dutkiewicz, S., Follows, M., and Oschlies, A.: Top-down control of marine phytoplankton diversity in a global ecosystem model, Prog. Oceanogr., 101, 1-13, doi:10.1016/j.pocean.2011.11.016, 2012.

Purves, D., Scharlemann, J. P. W., Harfoot, M., Newbold, T., Tittensor, D. P., Hutton, J., and Emmott, S.: Ecosystems: time to model all life on Earth, Nature, 493, 295-297, doi:10.1038/493295a, 2013.

Raitsos, D. E., Lavender, S. J., Pradhan, Y., Tyrrell, T., Reid, P. C., and Edwards, M.: Coccolithophore bloom size variation in response to the regional environment of the Subarctic North Atlantic, Limnol. Oceanogr., 51, 2122-2130, 2006.

Raitsos, D., Lavender, S., Maravelias, C., Haralabous, J., Richardson, A., and Reid, P.: Identifying four puhytoplankton functional types from space: an ecological approach, Limnol. Oceanogr., 53, 605-613, 2008.

Rost, B. and Riebesell, U.: Coccolithophores and the biological pump: responses to environmental changes, in: Coccolithophores - From Molecular Processes to Global Impact, edited by: Thierstein, H. R. and Young, J. R., Springer, Berlin, 76-99, 2004.

Sadeghi, A., Dinter, T., Vountas, M., Taylor, B. B., AltenburgSoppa, M., Peeken, I., and Bracher, A.: Improvement to the PhytoDOAS method for identification of coccolithophores using hyper-spectral satellite data, Ocean Sci., 8, 1055-1070, doi:10.5194/os-8-1055-2012, 2012.

Sarmiento, J., Dunne, J., Gnanadesikan, A., Key, R., Matsumoto, K., and Slater, R.: A new estimate of the $\mathrm{CaCO}_{3}$ to organic carbon export ratio, Global Biogeochem. Cy., 16, 1107, doi:10.1029/2002GB001919, 2002.

Sathyendranath, S., Watts, L., Devred, E., Platt, T., Caverhill, C., and Maass, H.: Discrimination of diatoms from other phytoplankton using ocean-colour data, Mar. Ecol.-Prog. Ser., 272, 59-68, 2004.

Silió-Calzada, A., Bricaud, A., and Gentili, B.: Estimates of sea surface nitrate concentrations from sea surface temperature and chlorophyll concentration in upwelling areas: a case study for the Benguela system, Remote Sens. Environ., 112, 3173-3180, doi:10.1016/j.rse.2008.03.014, 2008.

Sinha, B., Buitenhuis, E. T., Quéré, C. L., and Anderson, T. R.: Comparison of the emergent behavior of a complex ecosystem model in two ocean general circulation models, Prog. Oceanogr., 84, 204-224, doi:10.1016/j.pocean.2009.10.003, 2010.

Smith, W. and Pesant, S. (Eds.): MAREDAT - towards a world atlas of marine plankton functional types, Special Issue, Earth Syst. Sci. Data, 2012. 
Stal, L. J., Albertano, P., Bergman, B., von Bröckel, K., Gallon, J. R., Hayes, P. K., Sivonen, K., and Walsby, A. E.: BASIC: Baltic Sea cyanobacteria, an investigation of the structure and dynamics of water blooms of cyanobacteria in the Baltic Sea - responses to a changing environment, Cont. Shelf Res., 23, 1695-1714, doi:10.1016/j.csr.2003.06.001, 2003.

Strom, S.: Novel interactions between phytoplankton and microzooplankton: their influence on the coupling between growth and grazing rates in the sea, Hydrobiologia, 480, 41-54, doi:10.1023/A:1021224832646, 2002.

Strutton, P. G., Ryan, J. P., and Chavez, F. P.: Enhanced chlorophyll associated with tropical instability waves in the equatorial Pacific, Geophys. Res. Lett., 28, 2005-2008, 2001.

Takahashi, T., Sutherland, S. C., Sweeney, C., Poisson, A., Metzl, N., Tilbrook, B., Bates, N., Wanninkhof, R., Feely, R. A., Sabine, C., Olafsson, J., and Nojiri, Y.: Global sea-air $\mathrm{CO}_{2}$ flux based on climatological surface ocean $p \mathrm{CO}_{2}$, and seasonal biological and temperature effects, Deep-Sea Res. Pt. II, 49, 16011622, 2002.

Taylor, A. G., Landry, M. R., Selph, K. E., and Yang, E. J.: Biomass, size structure and depth distributions of the microbial community in the eastern equatorial Pacific, Deep-Sea Res. Pt. II, 58, 342357, doi:10.1016/j.dsr2.2010.08.017, 2011.

Telszewski, M., Chazottes, A., Schuster, U., Watson, A. J., Moulin, C., Bakker, D. C. E., González-Dávila, M., Johannessen, T., Körtzinger, A., Lüger, H., Olsen, A., Omar, A., Padin, X. A., Ríos, A. F., Steinhoff, T., Santana-Casiano, M., Wallace, D. W. R., and Wanninkhof, R.: Estimating the monthly $p \mathrm{CO}_{2}$ distribution in the North Atlantic using a self-organizing neural network, Biogeosciences, 6, 1405-1421, doi:10.5194/bg6-1405-2009, 2009.
Teoh, E., Tan, K., and Xiang, C.: Estimating the number of hidden neurons in a feedforward network using the singular value decomposition, IEEE T. Neural Networ., 17, 1623-1629, doi:10.1109/TNN.2006.880582, 2006.

Uitz, J., Claustre, H., Morel, A., and Hooker, S. B.: Vertical distribution of phytoplankton communities in open ocean: an assessment based on surface chlorophyll, J. Geophys. Res.-Oceans, 111, C08005, doi:10.1029/2005JC003207, 2006.

Vichi, M., Masina, S., and Nencioli, F.: A process-oriented model study of equatorial Pacific phytoplankton: the role of iron supply and tropical instability waves, Prog. Oceanogr., 78, 147-162, doi:10.1016/j.pocean.2008.04.003, 2008.

Wang, C. Z. and Fiedler, P. C.: ENSO variability and the eastern tropical Pacific: a review, Prog. Oceanogr., 69, 239-266, 2006.

Wells, M. L., Vallis, G. K., and Silver, E. A.: Tectonic processes in Papua New Guinea and past productivity in the eastern equatorial Pacific Ocean, Nature, 398, 601-604, 1999.

Whitton, B. and Potts, M.: The Ecology of Cyanobacteria: Their Diversity in Time and Space, Kluwer Academic Publishers, 2000.

Zhang, H. M., Bates, J. J., and Reynolds, R. W.: Assessment of composite global sampling: sea surface wind speed, Geophys. Res. Lett., 33, L17714, doi:10.1029/2006GL027086, 2006. 